
\title{
Reseserch Suare \\ Regional Forecast of China's Carbon Emission Peak in 2030 and Analysis of Influencing Factors
}

Dawei Wang ( $\square$ wdwnangjing@163.com )

Nanjing Forestry University

Wenxing Shen

Nanjing Forestry University

Shengliang Zhang

Nanjing Forestry University

\section{Research Article}

Keywords: $\mathrm{CO} 2$ emissions peak, Scenario analysis, DEA, Four regions of China, Generalized divisia index method

Posted Date: July 8th, 2021

DOI: https://doi.org/10.21203/rs.3.rs-627141/v1

License: (9) This work is licensed under a Creative Commons Attribution 4.0 International License. Read Full License 
Regional Forecast of China's Carbon Emission Peak in 2030 and Analysis of Influencing Factors

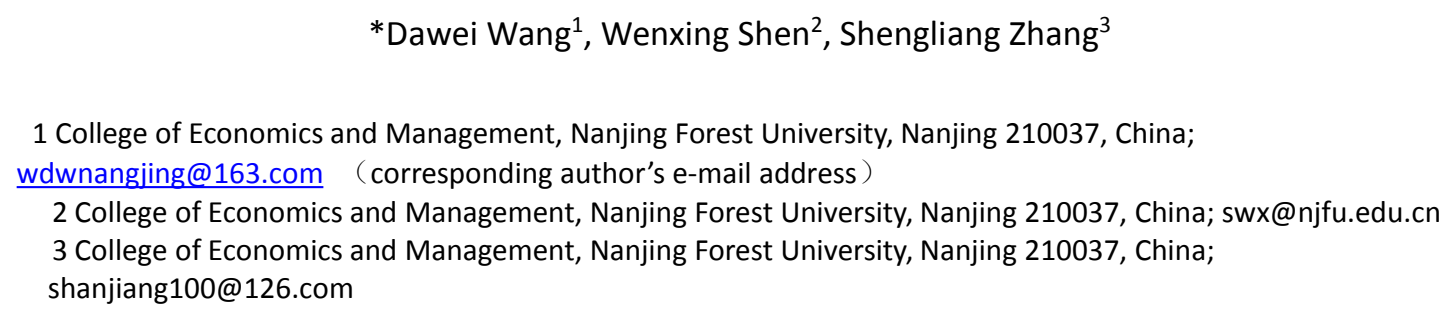

Abstract: In this article, we firstly analyzed the historical development trends, regional economies, population, urbanization and carbon emissions of the four major regions which are the East, the Middle, the North-east and the West, respectively. Then we compared China's environmental Kuznets curve both in home and abroad, found that the relationship between economic development and pollution emissions varies from regions and countries. We used the IPAT model to design 48 peak $\mathrm{CO}_{2}$ emission scenarios in order to get to more comprehensive depict of future development path of China's carbon emissions. Furthermore, we used a centralized DEA to evaluate the allocative efficiency of scenario-based $\mathrm{CO}_{2}$ emission paths. As a consequence, we found that maintaining relatively high GDP growth (around 6\%), reducing energy intensity by about $75 \%$ of average annual decline rate(around 4\%); and increasing non-fossil energy to $21 \%$ to meet the Innovation plan of energy technology revolution 2016-2030 requirements is the most efficient low-carbon behaviors towards 2030 peak $\mathrm{CO}_{2}$ 
emissions of $10.57 \mathrm{Gt}$. We also found that China can potentially reduce $\mathrm{CO}_{2}$ emission intensity (CEI) by up to $72.7 \%$ compared to the 2005 level in 2030, and therefore that official CEI reduction targets (60-65\%) are well within reach. It is also found that in the future path of the predicted optimal scenario, only economic scale and low carbon per unit output value have a great contribution to the changes in carbon dioxide emissions.

Keywords: $\mathrm{CO}_{2}$ emissions peak; Scenario analysis; DEA; Four regions of China; Generalized divisia index method

8

9
1 42 43 45 46 7 8 49 
Introduction

\section{Global carbon emissions continue to grow rapidly}

According to the International Monetary Fund World Economic Outlook (2019), world carbon dioxide emissions rose further in 2017 after a decade or so of steady growth, with global carbon emissions increasing by $1 \%$ in 2017 and continuing to increase in 2018 . With the increase of atmospheric carbon dioxide concentration, the global threat of the greenhouse effect has increased further, a trend that has put the world on a dangerous path. Therefore, curbing greenhouse gas emissions is important to control global temperature rise and prevent catastrophic climate events, and the greenhouse effect should be the sword of Damoaklis for global sustainability.

\section{China is a big carbon emitter}

According to Global Carbon Atlats (2019), China has become the world's largest emitter of greenhouse gas emissions for 13 consecutive years since it over steed the United States in 2006. In 2018, China's carbon dioxide emissions have reached 100. 6.5 billion tons, accounting for $26.95 \%$ of the world's total emissions, more than $85.5 \%$ of the total emissions of the second-largest carbon emitter. Thus, China will play an important role in whether the global greenhouse effect can be effectively controlled. Meanwhile, China's government has taken steps to better meet 


\begin{tabular}{|c|c|c|}
\hline Time & Actions to reduce emissions & Emission reduction targets \\
\hline 2009 & $\begin{array}{l}\text { Released the "12th Five-Year } \\
\text { Plan" to Control Greenhouse } \\
\text { Gas Emissions; }\end{array}$ & $\begin{array}{c}\text { Carbon intensity will be } 17 \% \\
\text { lower in } 2015 \text { than in } 2010\end{array}$ \\
\hline 2011 & $\begin{array}{l}\text { Attended the Copenhagen } \\
\text { Climate Change Conference }\end{array}$ & $\begin{array}{l}\text { Reduce carbon intensity by } \\
40 \%-45 \% \text { from } 2015 \text { by } 2020\end{array}$ \\
\hline 2014 & $\begin{array}{l}\text { Released the "Joint Voice on } \\
\text { Climate Change between China } \\
\text { and the United States" }\end{array}$ & $\begin{array}{l}\text { Peak carbon emissions } \\
\text { around } 2030 \text { and increase the } \\
\text { proportion of non-fossil } \\
\text { energy use to } 20 \%\end{array}$ \\
\hline 2015 & $\begin{array}{l}\text { Attended the Paris Climate } \\
\text { Change Conference }\end{array}$ & $\begin{array}{l}\text { China will reduce carbon } \\
\text { intensity by } 60 \%-65 \% \text { by } \\
2030 \text { compared to } 2005\end{array}$ \\
\hline
\end{tabular}

its emissions reduction responsibilities a range of emission reduction actions, as shown in table 1:

Table 1, China's emissions reduction targets

\section{China is under pressure from both economic development and}

\section{energy conservation and emission reduction}

Although China produces the world's second largest GDP, but is still a developing country that its per capita GDP has not yet entered a high income level, China still needs economic development as the main focus. At present, most of the energy used in China is still coal with a high carbon emission coefficient per unit of energy. The aim of achieving the emission reduction target of carbon dioxide emissions peak and meet the growth of energy demand seems to be the conflict between spear of energy conservation and emission reduction.

How to solve the above difficulties? That will require the Chinese 
government to vigorously promote the research on application of energy-saving and emission-reduction technologies to achieve a reduction, in carbon emissions per unit of energy as economic growth takes. Energy conservation and emission reduction targets under rapid economic growth can be effectively achieved only if both the input side (controlling energy consumption) and the output side (reducing carbon emissions per unit of energy output) are controlled.

\section{China's regional development is uneven}

China's vast territory, not only causes different geographical environment but also resulting in China's economic development level and environment are different. Because the eastern region is closer to the port, so it is easier to carry out foreign trade activities, but also easier access to more advanced production technology, according to Ricardo's theory of comparative advantage. According to the development of trade, regardless of the region's product productivity between the two sides is low or high, as long as there is a comparative advantage of input and output between goods to enhance the overall output capacity of both sides of the trade, and further enhance the professional division of labor capacity of products. Because the eastern region has certain geographical advantages and policy advantages, the eastern part of China has better economic development than the central and western regions far from the port. 
When China formulates its carbon emission control policy, different regional foundations must be taken into account, such as economic development level, industrial structure, technology level, energy structure and other factors, so as to better formulate regional emission reduction policies suitable for different development environments.

As a consequence, concerning the 2030 China's carbon emission peak and emission reduction target allocation research, mainly focused on the 2030 national or local carbon emission peak research, or the national or regional industry carbon emission path research. These above researches often involve a relatively single region, most of the research is for a specific region of the industry, or the country's specific industry carbon emission path research, lack of the national sub-regional vision of the peak carbon emission path to carry out systematic research, therefore, the research dimension is not enough to deepen. These studies can not meet the Chinese government's policy reference needs for achieving the 2030 carbon emission peak target. After all, China in the formulation of carbon emission reduction program, is to carry out overall planning. However, as for carbon emission reduction policy formulation, must take into account the heterogeneity of regional development, in order to truly formulate an integrated carbon emission reduction policy.

Therefore, this paper will consider China's development strategy in recent years, the four regions including a total of 30 provinces and cities 
131 (due to lack of data, excluding Tibet, Hong Kong, Macao, Taiwan), and

consider the historical development of each region on the region's carbon emissions in the future development trend of the driving effect, At the same time, in order to better achieve the emission reduction target, we will explore in depth the impact of China's four major regional carbon emission factors on carbon emission changes, based on scenario analysis, from the historical and future perspectives of the impact of carbon emissions on each region.

\section{Material and Method}

\section{IPAT Model}

Many studies have been carried out by domestic and foreign scholars on the factors affecting carbon emissions in a country or region. The main tool used in the study of this problem is the IPAT model. In 1970, Ehrlich W (1971), first proposed the IPAT model to study the effects of human activities on the natural environment. He believes that the pollutants emitted by human beings are mainly caused by factors such as population size, economic development level and scientific and technological level. Subsequently, Waggoner and Ausubel (1999), sound on the basis of the traditional IPAT model, the Impact Analysis model is proposed. In their view, factors affecting the natural environment should include factors such as consumption and efficiency of use per unit of output, in addition 
to population, affluence and skill levels.

\section{Environment Kuznets Curve Theory}

The Environmental Kuznets Curve originated from Grossman and Krueger's (1991) study of the relationship between environmental pollution and economic growth, and the two scholars firstly discovered the inverted U-shaped relationship between environmental pollution and economic growth. Stem (2015) discusses the relationship between factors related to environmental pollution and develops the research results into the environmental Kuznets Curve (EKC) theory. The environmental Kuznets curve theory shows that the primary stage of economic development will be developed at the expense of the environment, but when the level of economic development reaches a certain level, society begins to improve the relationship between economy and environment, and the degree of environmental degradation decreases. In the advanced stage of economic development, economic growth and environmental pollution are decoupling. From a very simple point of view, it can show that economic growth is good for the environment.

In short, when the region's economic development to a certain level, people will put forward a higher standard for their living environment, will increase the development of energy conservation and environmental protection and low-carbon technology, so that the per unit of GDP pollution emissions fell more than the magnitude of GDP growth. Thus, 
reaching the inflection point of the environmental Kuznets curve. The birth of the environmental Kuznets theory provides the theoretical basis for the world to achieve the peak of carbon emissions while maintaining economic growth.

\section{Data envelopment analysis}

The potential to reduce carbon dioxide emissions determines how the task of reducing carbon dioxide emissions is allocated, and the rational allocation of carbon emissions is also relevant to China's ability to achieve a peak carbon emissions by 2030. Data envelopment analysis (DEA) is often used to measure $\mathrm{CO}_{2}$ reduction potential. Zhou and others (2007) proposed an environmental DEA model based on relaxation variables to simulate the performance of $\mathrm{CO}_{2}$ emissions when the economy is inefficient. Guo(2011) used the DEA model, from the perspective of energy-saving technology and energy structure changes, measured the emission performance of 29 provinces and cities in China. Miao and other (2016) used ZSG-DEA model to measure the distribution of carbon emissions in different provinces of China. Wang and others (2014) have allocated $\mathrm{CO}_{2}$ emissions from 30 provinces and cities in China in a fixed amount, and have recommended that different provinces and cities bear different responsibilities for reducing emission intensity and non-fossil fuel share, such as Zhou (2014), using Centralized-DEA to 
determine the optimal path for China to control $\mathrm{CO}_{2}$ emissions at the provincial and regional levels. They found an inverted u-shaped relationship between overall optimal GDP and emissions control coefficients, suggesting that the more developed regions of the economy, the more responsible they should be for reducing emissions.

\section{Literature review}

\section{The theory of sustainable development}

Sustainable development is a necessary prerequisite for the long-term development of mankind, and it is to maintain the stability of the ecological environment while providing the long-term process for human activities to meet the needs of its economic and social development. The desired result is a social state in which the living environment and resources can be sustained to meet human needs without undermining the integrity and stability of the natural system. Sustainable development can be defined as a way of development that meets the needs of contemporary life and production without sacrificing the living environment and production conditions of future generations.

Sustainable development theory can be applied to many fields of research, the use of any scarce resources should consider sustainable issues, such as the rational use and protection of water resources, mineral oil resources development and maintenance, forest resources felling and 
cultivation. In order to coexist harmoniously between human beings and the earth's ecological environment for a long time, all kinds of economic activities that need to use natural resources for production inputs can be applied without sustainable development theory.

\section{Carbon emissions peak research}

Some researchers in China believe that future energy consumption will continue to increase carbon dioxide emissions, making it difficult for $\mathrm{CO}_{2}$ emissions to peak by 2030. $\mathrm{BP}$ (2018) predicts that China is on track to reach a peak of carbon dioxide emissions by 2025, peaking at about 10 billion tons. Li and others (2017) suggest that China's carbon emissions will peak at 11.2 billion tons in 2026 and reduce their carbon dioxide emissions by 21.64 billion tons between 2015 and 2035. Martin and Chen (2017) used the Time S models to predict China's carbon emissions peak path, and concluded that China will reach a peak of $\mathrm{CO}_{2}$ emissions around 2030, peaking at around 10-10.8 billion tons. Due to the different regional development foundations, there may be significant differences in carbon emission paths in different regions. Du and others (2017) have studied the trend of $\mathrm{CO}_{2}$ emissions, and believe that carbon dioxide emissions in Beijing and Shanghai have reached their peak. Yang and others. (2015) point out that Beijing is likely to peak in 2019. Gao and others (2016) predict that Shandong Province will reach its peak by 2024 
under the energy-saving scenario. It may not peak until 2030 or later.

\section{Carbon emissions and the economy grow}

carbon emissions, different scholars have different conclusions according

246 to the different subjects of the study. Grossman and Krueger (1991)

247 studied the relationship between environmental pollution and economic

248 growth and found an inverted $\mathrm{u}$-shaped trend between the two. However,

249 studies such as Churchill et al. (2018) have shown that there are other

250 relationships between environmental pollution and drivers (e.g. linear, U,

$251 \mathrm{~N}$, inverted N-shaped) ".The various shapes present in different studies

252 can be attributed to regional differences, and the EKC curves distributed

253 across subregions will form the economic growth and carbon emission

254 curves of the entire region."

255 In some regions, the EKC curve is difficult to identify, and Ozokcu 256 and Ozdemir (2017) studied the EKC curve of economic growth and 257 carbon emissions and found no significant correlation between the two. 258 Olale and others (2018) analyzed the relationship between Carbon 259 Emissions and Driving Factors in Canada and found that U-type and 260 reverse U-type can describe the relationship between per capita 261 greenhouse gas emissions, income and technological change. 


\section{The scale of economic development in the four major regions}

Regional GDP can be used as a measure of the size of the economy, since the time span of our study is from 2009-2019, in order to better consultant the four major regions of 2009-2019 GDP as shown in figure 1. illustrate the real economic growth of the regions during this period, we 1.

Figure 1, GDP of the four major regions from 2009 to 2019

274

implementing the first development strategy in the east is shaking ahead.

And by the end of 2019, the GDP of the four region was about 32.82

276 trillion yuan in East, 12. 02 trillion yuan in Middle, 11. 68 trillion yuan in

277 West and the North-east took the lowest point for around 5.04 trillion 278 yuan. It is obvious that the eastern region's economy accounted for roughly $53.31 \%$ of the country's economy, while the eastern region's GDP

280 in 2015 increased by 19.49 trillion yuan compared while the GDP of the 
other three regions increased by 17.94 trillion yuan. The Eastern region implementing the central rise strategy is similar to the total GDP of the western development strategy region, and the trend of economic growth is similar in 2015. The region with the lowest total GDP and the fewest provinces and cities covered by the northeast strategy.

\section{The level of economic development in the four major regions}

The level of economic development of the region can be measured by GDP per capita, as can be found in Figure 2, in the four regions, the Eastern region is not only the first in total, but also the first in GDP per capita.

Figure 2, GDP per capita in the four regions from 2009 to 2019

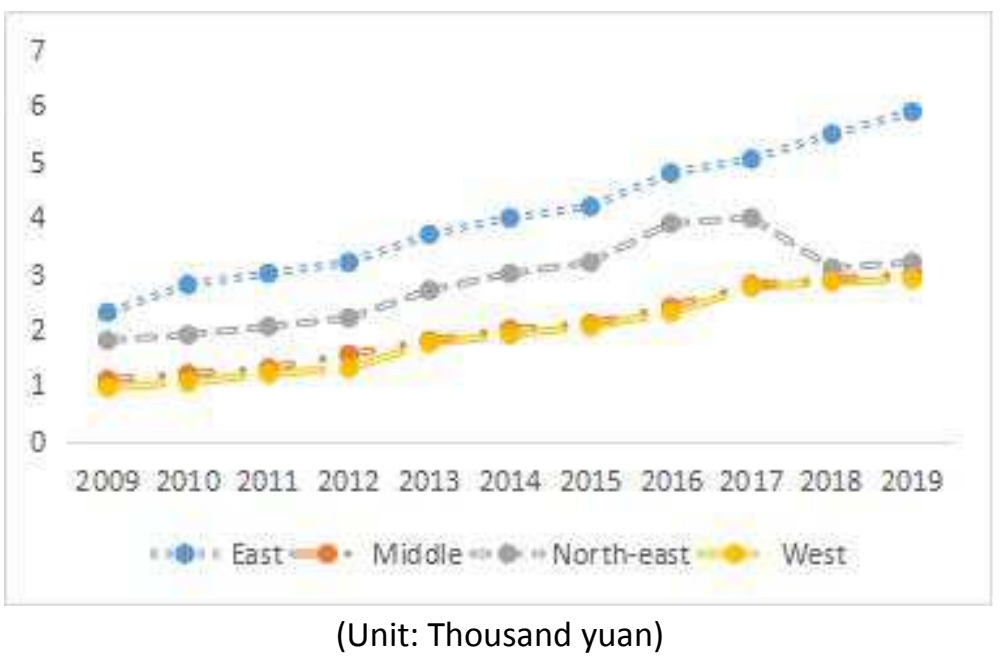

\section{Population size and level of urbanization}

Combined with the level of economic development, it can be found that in the four regions, the higher the level of economic development, the higher the rate of urbanization.

Figure 3, Percentage of population in each region in 2019 
As figure 3 demonstrates, in 2019, the eastern region had the highest 303 proportion of the population, accounting for about $38.4 \%$ of the total 304 population, while the eastern region also had the highest level of urbanization, at $68.38 \%$. The Northeastern region has the smallest percentage of the population in the country, accounting for only $8 \%$, but 307 the North-east, an old industrial base, has a high level of urbanization, 308 second only to the East, at $60.49 \%$, about $10 \%$ higher than the Middle 309 and West.

310 The rate of population growth can reflect the rate of natural 311 population growth in a region and the degree of attraction to the 312 population.

Figure 4, Proportion of urbanization in each region in 2019 

growth.

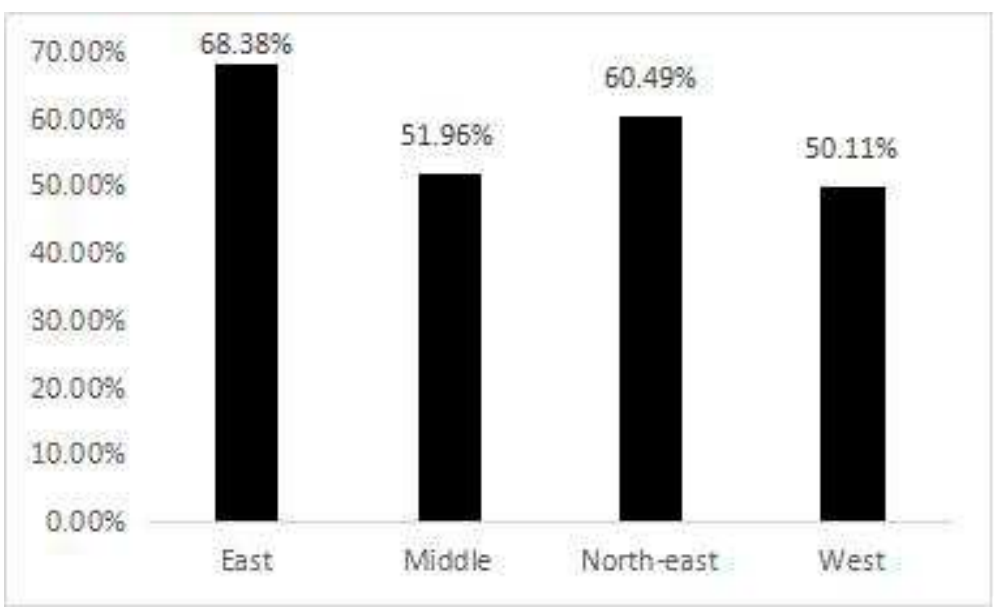

As shown in Figure 4, the population growth rate in the East was higher than the national average during the period of 2010-2019, while the population growth rate in the Middle, West and North-east was lower. Figure 5, Regional and national population growth rates from 2010 to 2019

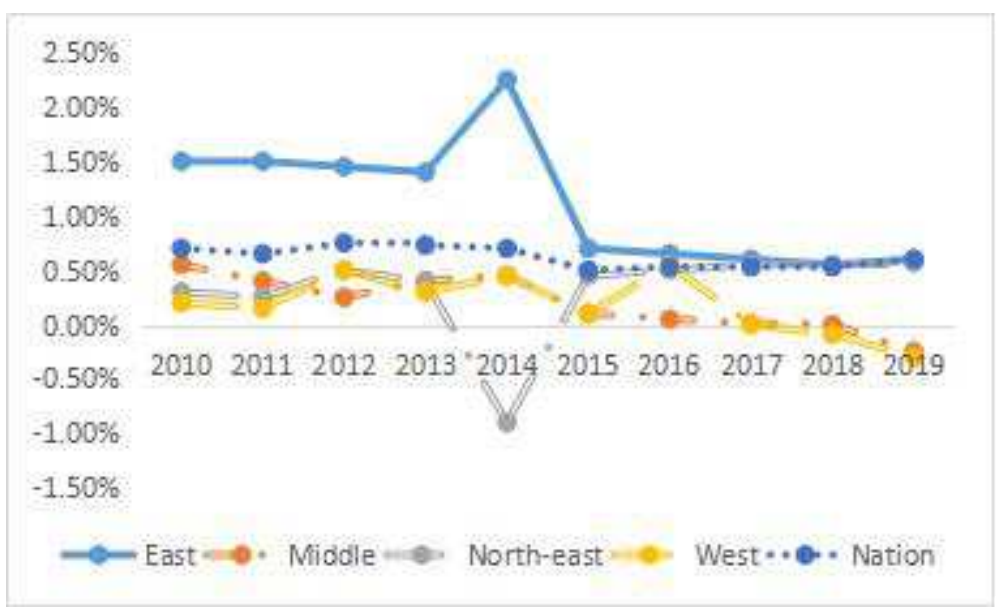

However, the population growth rate in the northeast region is gradually deviating from the average according to figure 5, which shows that the development environment in the northeast region is becoming less and less attractive to the population, resulting in negative population 


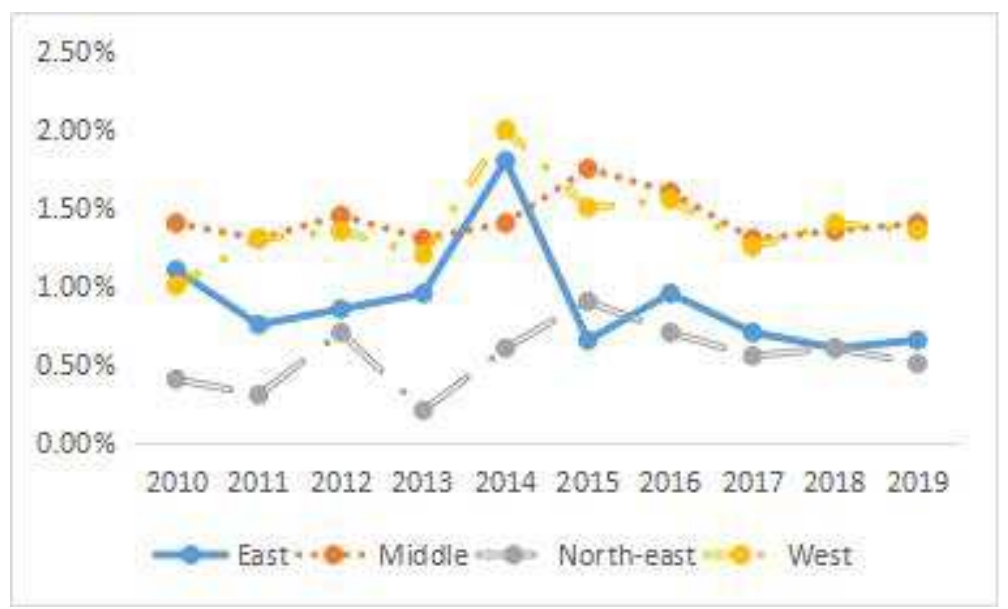

Urbanization in all four regions is growing, but the growth rate is highly volatile. As shown in Figure 6, the central and western regions with the lowest level of urbanization have a relatively high urbanization growth rate of about $1.5 \%$.

\section{Carbon emission characteristics}

As shown in Figure 7, the size of $\mathrm{CO}_{2}$ emissions in the four regions is in the same order as the size of the population in each region, with the highest and largest increases in $\mathrm{CO}_{2}$ emissions in the East between 2010 and 2019.The scale of $\mathrm{CO}_{2}$ emissions in Northeast has been at its lowest level. Judging from the trend of $\mathrm{CO}_{2}$ emissions in all regions from 2010 to 2019, the growth rate of $\mathrm{CO}_{2}$ emissions in the four regions has stabilized.

Figure 7, Regional $\mathrm{CO}_{2}$ emissions trends from 2010 to 2019 


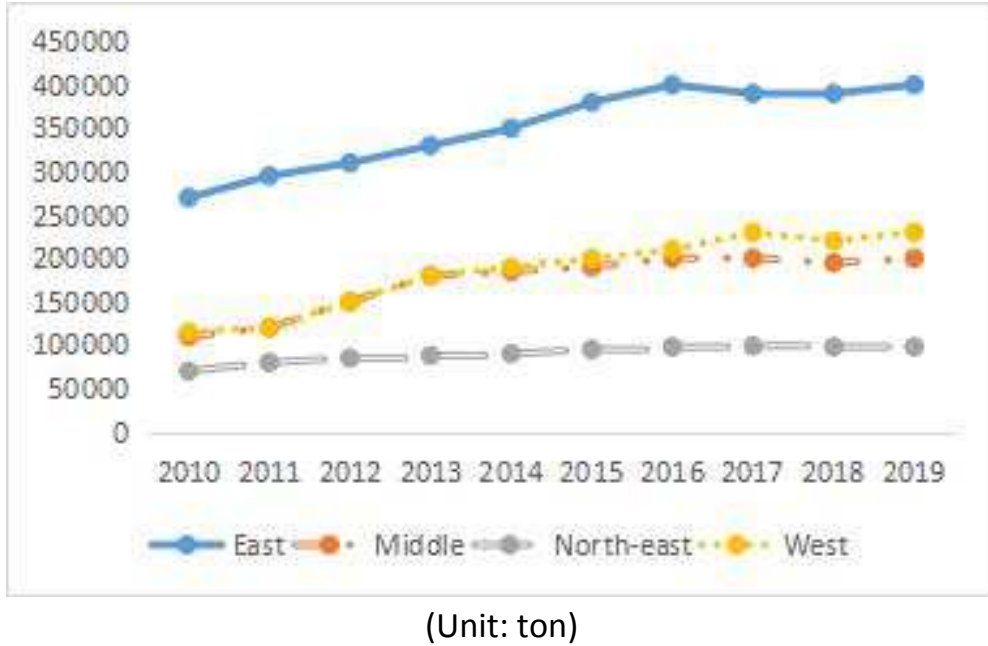

\section{Carbon intensity}

The carbon intensity in the central region is significantly lower than that in the West, indicating that the industrial structure of the Middlel and West is significantly different. The highest GDP per capita and the lowest carbon intensity indicate that the eastern region has the most intensive and efficient economic development path, shown in figure 8.

Figure 8, Regional carbon intensity trends

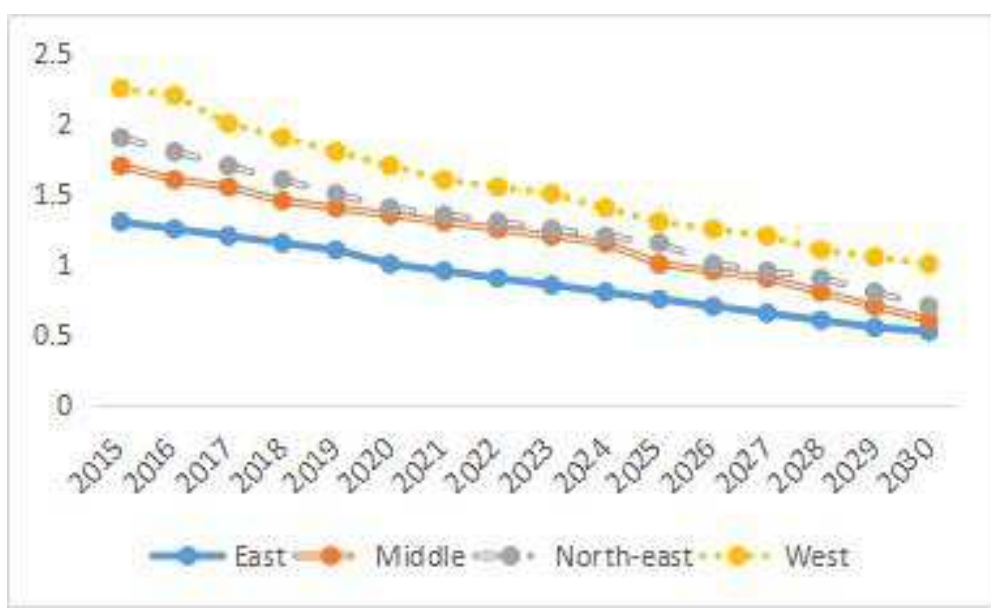

Moreover, as shown in figure 8 , the West has the highest carbon intensity, probably because its economic development is more dependent on energy-intensive industries, and the Middle's carbon intensity is nearly one unit less than that of the West, which shows that although the scale 
and level of economic development in the Middle and West regions are

358 similar.

359

370 development and pollution emissions, which is the cornerstone of our

371 research and provides theoretical support for China to achieve a peak in

$372 \mathrm{CO}_{2}$ emissions while maintaining economic growth. 


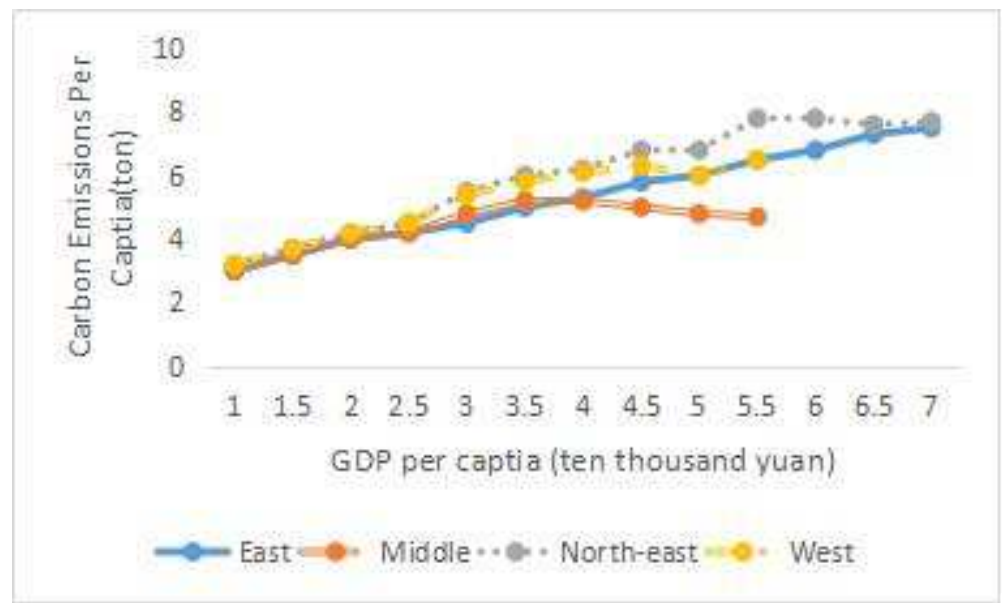

(Data source: World-Economic-Outlook-october-2019, WEO 2019)

Figure 9 represents the environmental Kuznets curve of the four regions, the horizontal axis is the per capita GDP of each region, symbolizing the level of economic development of each region, the vertical axis is per capita carbon dioxide emissions, symbolizing the level of pollution emissions. The four segments are the environmental Kuznets curve for each region, with a total of 10 points per segment.

The first point to the right at the far left of each segment represents the level of $\mathrm{CO}_{2}$ emissions and economic development in each region from 2010 to 2019. As can be found, the level of economic development in each region has been increasing from 2010 and 2019, but the increase in $\mathrm{CO}_{2}$ emissions in each region has gradually slowed, and the Kuznets curve in each region has levelled off, which provides the possibility for each region to meet the peak target of 2030 .

The environmental Kuznets curve of each region is not consistent. First of all the environmental Kuznets curve in the Northeast is on the top at the level of economic development and the corresponding carbon 
emission than the other three regions. So it can be inferred that the economic development path of the Northeast is the least intensive and environmentally friendly.

The corresponding level of economic development and carbon emissions in the West in 2019 is similar to that of the in the Middle, but the carbon emission level is significantly lower than that in the West. And since 2011, the carbon emission level in the Middle is lower than that in the East at the same level of economic development, indicating that the Middle has the most environmentally friendly economic development route at the same level of economic development.

To sum up, the economic development in East is the most advanced; the Middle is the most environmentally friendly one which should continue to maintain advantages to increase the energy-saving and environmental protection technology. Then, the Northeast and West region may need to learn the emission reduction path of improving low-carbon level of economic development.

\section{Scenarios design}

\section{Introduction of the analyzing methods}

The IPAT model is an economic model proposed by ecologists Ehrlich and Holdren (1971) to analyze the effects of population growth, economic development, and technological progress on the ecological 
414 environment. Many scholars use IPAT models to identify key drivers of 415 pollutant emissions at the national, regional, and industrial levels. 416 Similarly, this model can be used to predict future pollution emission 417 paths based on trends in different key drivers, and there are many 418 scholars (Commoner, 1972; Dietz and Rosa, 1997; Guan, etc., 2008). To 419 use this model to predict future trends in China's pollution emissions o 420 IPAT model is actually an abbreviation for a simple one-equation: IPAT, 421 where the letter 'I' stands for environmental impact (impact), 'P' for 422 population, ' $A$ ' for affluence (affluence), ' $T$ ' for environmental 423 technology (technology). In this paper, the IPAT model is used to predict 424 the carbon dioxide emissions in the four regions and the whole country 425 under the uncomal scenario. The model is as follows:

$$
\mathrm{I}=P * A^{*} T
$$

This paper focuses on carbon emissions, so the environmental

This formula is the Kaya constant equation, proposed by the 435 Japanese scholar Yoichi Kaya (1990) (V), widely used to assess the 
436 factors affecting pollution emissions, $\mathrm{C}$ is $\mathrm{CO}_{2}$ emissions. When the 437 effects of population factors on $\mathrm{CO}_{2}$ emissions are not taken into account, 438 the Kaya formula is distorted to:

$$
\mathrm{C}=G \frac{E}{G} \frac{C}{E}
$$

The rate of change of the drivers is added to formula 1-4, and the time factor can be used to predict $\mathrm{CO}_{2}$ emissions from future regions:

According to the above formula (1-5), $\mathrm{r} 、 \mathrm{~g} 、 \mathrm{v}$, represent the average annual rate of change of GDP, energy intensity and carbon emission per unit of energy consumption, respectively. This paper applied GDP, energy intensity, carbon dioxide emissions per unit of energy dioxide emissions 447 in the future annual rate of development scenario design. And then dioxide emissions in the four regions under different scenarios.

Figure 10, The GDP growth rate of the four regions and the whole 
457

\begin{tabular}{ccccc}
\hline Organization & $2016-2020$ & $2021-2025$ & $2025-2030$ & $2031-2040$ \\
\hline $\begin{array}{c}\text { China Energy Research } \\
\text { Association } \\
(2016)\end{array}$ & $6.8 \%$ & $5.5 \%$ & $4.5 \%$ & - \\
$\begin{array}{c}\text { World Bank } \\
(2012) \\
\text { Mckinsey } \\
\quad(2009)\end{array}$ & $7 \%$ & $5.9 \%$ & $5.0 \%$ & - \\
$\begin{array}{c}\text { International Energy Agency } \\
(2014) \\
\text { British Oil } \\
(2018)\end{array}$ & - & $6.5 \%$ & $6.5 \%$ & - \\
\hline
\end{tabular}

461

462 463 464 development, as shown in table 3:

465

Table 3, China's GDP Development Scenario

\begin{tabular}{cccccc}
\hline Scenario & $2016-2020$ & $2021-2025$ & $2026-2030$ & $2031-2040$ & Average \\
\hline A1 (Rapid) & $7.0 \%$ & $6.0 \%$ & $5.0 \%$ & $4.0 \%$ & $6 \%$ \\
A2 (Moderate) & $6.5 \%$ & $5.5 \%$ & $4.5 \%$ & $3.5 \%$ & $5.5 \%$ \\
A3 (Low) & $6.0 \%$ & $5.0 \%$ & $4.0 \%$ & $3.0 \%$ & $5 \%$ \\
\hline
\end{tabular}


During the years of 2009-2019, GDP in the East, the Middle, the

468 Northeast, the West and the Nationwide grew at an average annual rate of $10.77 \%, 11.6 \%, 10.65 \%, 12.35 \%$ and $11.20 \%$. At the same time, the economic growth rate of the four regions is gradually slowing down, 471 taking into account the heterogeneity of regional economic development, 472 we assumed that under different economic growth scenarios, the 473 economic growth rate of each region will remain proportional to the GDP 474 growth rate of the corresponding scenario. The relative proportion of 475 GDP growth in the four regions is calculated on the basis of the average 476 annual GDP growth rate for each of their regions for the decade of 477 2010-2019. The future GDP growth rate of each region can be calculated 478 by formula (4-6):

$$
\mathrm{S}_{\mathrm{i}}^{\mathrm{t}}=S_{z}^{t} \frac{S_{i}^{2010-2019}}{S_{z}^{2010-2019}}
$$

In this formula, $i=4-1$ represents four regions, and $481 t=2019 / 2020 / 2021 / 2025 / 2026 / 2030 / 2031-2040$ represents the time 482 interval involved in the forecast: the $\mathrm{S}_{i}^{\mathrm{t}}$ and $\mathrm{S}_{z}^{\mathrm{t}}$ represent the growth rate of regional ' $i$ ' and national GDP within the period of ' $t$ ', respectively. The economic growth rate of the four regions will remain relative to the 485 projected GDP growth rate of the whole country, and the GDP growth 486 rate of the four regions and the whole country will remain unchanged duo 487 to the the relative proportion of $\mathrm{S}_{\mathrm{i} 2010-2019} / \mathrm{S}_{\mathrm{z} 2010-2019}$. Based on this formula, 
488

\begin{tabular}{cccccc}
\hline Scenario & Region & $2016-2020$ & $2021-2025$ & $2025-2030$ & $2031-2040$ \\
\hline \multirow{3}{*}{ A1 } & East & $6.73 \%$ & $5.77 \%$ & $4.81 \%$ & $3.85 \%$ \\
& Middle & $7.25 \%$ & $6.21 \%$ & $5.18 \%$ & $4.14 \%$ \\
& North-east & $6.65 \%$ & $5.70 \%$ & $4.75 \%$ & $3.80 \%$ \\
& West & $7.72 \%$ & $6.62 \%$ & $5.51 \%$ & $4.41 \%$ \\
\hline \multirow{3}{*}{ A2 } & East & $6.25 \%$ & $5.29 \%$ & $4.33 \%$ & $3.37 \%$ \\
& Middle & $6.73 \%$ & $5.70 \%$ & $4.66 \%$ & $3.62 \%$ \\
& North-east & $6.18 \%$ & $5.23 \%$ & $4.28 \%$ & $3.33 \%$ \\
& West & $7.17 \%$ & $6.06 \%$ & $4.96 \%$ & $3.86 \%$ \\
A3 & East & $5.77 \%$ & $4.81 \%$ & $3.85 \%$ & $2.89 \%$ \\
& Middle & $6.21 \%$ & $5.18 \%$ & $4.14 \%$ & $3.11 \%$ \\
& North-east & $5.70 \%$ & $4.75 \%$ & $3.80 \%$ & $2.85 \%$ \\
& West & $6.62 \%$ & $5.51 \%$ & $4.41 \%$ & $3.31 \%$ \\
\hline
\end{tabular}

the GDP growth rate of the four regions in each scenario can be calculated over different forecast periods, as shown in table 4:

Table 4, Forecasts of GDP growth under different scenarios in the four regions
492

\section{Energy intensity scenario design}

From the historical data on energy intensity from 2010 to 2019 (Figure 11), we can see that the energy intensity of the four major regions of the country is declining at an average annual rate of $5 \%$ to $6 \%$, and the annual energy intensity decline rate of each region during the decade is $5.61 \%$ in the East, $5.55 \%$ in the Middle and $5.95 \%$, although the rate of $5.14 \%$ degrees in the West is almost similar.

However, there is a clear difference between the absolute amount of energy intensity among the regions. The East with the highest per capita GDP has the lowest energy intensity, while the West with the lowest per 
capita GDP has the highest energy intensity.

Figure 11, Energy intensity in four major regions from 2010 to 2019

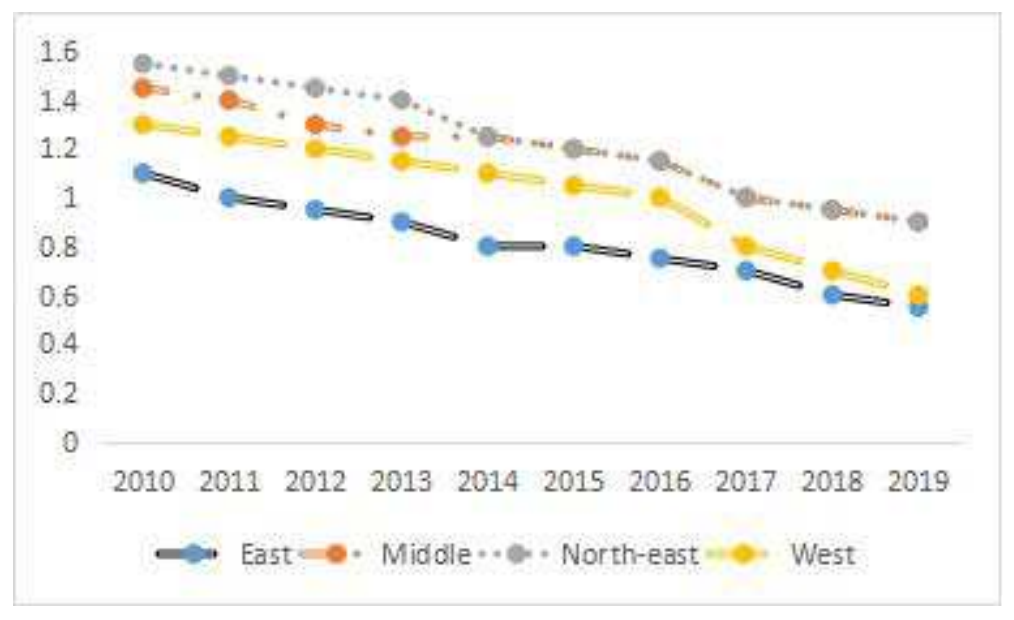

In 2019, the energy intensity of the West is even higher than that of the eastern region in 2010, considering that with the continued implementation of the four regional energy conservation and emission reduction strategies in the future, the energy efficiency of all regions of China will be further improved, and the energy intensity will continue to decline. As there may be few concrete forecasts for the decline rate of energy intensity in the future regions. Meanwhile, in order to better describing all possible scenarios of energy intensity changes in various regions of China in the future, the energy intensity decline rate in the four regions based on Figure 12 in 2010-2019 has designed the future development scenarios of energy intensity in four regions of China. Figure 12, The rate of energy intensity decline in the four regions from 2010 to 2019 


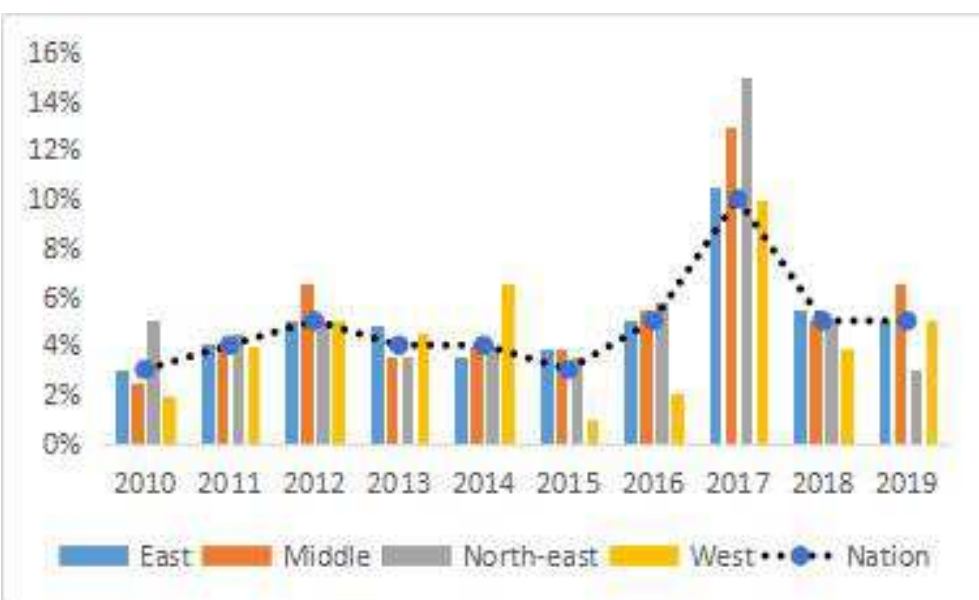

Considering that the potential for future energy intensity decline

decreases with the implementation of emission reduction control policies,

524 it is more appropriate to set the high-speed decline scenario of energy

525 intensity based on the average energy intensity decline rate of each region

526 from 2010 to 2019 . For the purpose of covering more forecast intervals,

527 design scenarios using the quarterback method, the lower rate of the

528 medium-speed scenario is $75 \%$ of the high-speed scenario, the rate of

529 decline of the low-speed scenario is $50 \%$ of the high-speed scenario.

530 The average annual decline in energy intensity in the four regions

531 from 2016 to 2040 is shown in table 5.

Table 5, Regional Energy Intensity Development Scenario

\begin{tabular}{ccccccc}
\hline Scenario & $\begin{array}{c}\text { Changing } \\
\text { Rate }\end{array}$ & Region & $\begin{array}{c}2016- \\
2020\end{array}$ & $\begin{array}{c}2021- \\
2025\end{array}$ & $\begin{array}{c}2025- \\
2030\end{array}$ & $\begin{array}{c}2031- \\
2040\end{array}$ \\
\hline \multirow{3}{*}{ B1 } & & East & $5.61 \%$ & $5.47 \%$ & $5.33 \%$ & $5.19 \%$ \\
& Rapid & Middle & $5.55 \%$ & $5.41 \%$ & $5.27 \%$ & $5.13 \%$ \\
& (about & North-east & $5.95 \%$ & $5.80 \%$ & $5.65 \%$ & $5.50 \%$ \\
& $5.0 \%)$ & West & $5.14 \%$ & $5.01 \%$ & $4.88 \%$ & $4.76 \%$ \\
B2 & Moderate & East & $4.21 \%$ & $4.10 \%$ & $4.00 \%$ & $3.89 \%$ \\
& Middle & $4.16 \%$ & $4.06 \%$ & $3.95 \%$ & $3.85 \%$ \\
& (about & North-east & $4.46 \%$ & $4.35 \%$ & $4.24 \%$ & $4.13 \%$ \\
& $4.0 \%)$ & West & $3.86 \%$ & $3.76 \%$ & $3.66 \%$ & $3.57 \%$ \\
\hline
\end{tabular}




\begin{tabular}{ccccccc}
\hline B3 & Low & Middle & $2.77 \%$ & $2.70 \%$ & $2.64 \%$ & $2.57 \%$ \\
& (about & North-east & $2.97 \%$ & $2.90 \%$ & $2.82 \%$ & $2.75 \%$ \\
& $2.5 \%)$ & West & $1.29 \%$ & $1.25 \%$ & $122 \%$ & $1.19 \%$ \\
\hline
\end{tabular}

533

534

535

$551=\frac{E_{\text {coal }}}{E} * r_{\text {coal }}+\frac{E_{\text {oil }}}{E} * r_{\text {oil }}+\frac{E_{\text {gas }}}{E} * r_{\text {oil }}+\frac{E_{\text {clean }}}{E} * r_{\text {clean }}$ 
$\mathrm{E}_{\text {coal }}, \mathrm{E}_{\mathrm{oil}}, \mathrm{E}_{\mathrm{gas}}, \mathrm{E}_{\mathrm{clean}}$ Representing the region's energy consumption of coal, oil, natural $r_{\text {coal }}, r_{\text {oil }} r_{\text {gas }}, r_{\text {clean }}$ as carbon emission factors for each energy source, according to the Intergovernmental Panel on Climate Change (IPCC) released in 2016 includes carbon emission factors of 2.64, 2.08, 1.63, 0 tonnes/standard coal tonnes for coal, oil, natural gas and clean energy. The formula (1-7) dedes the $\mathrm{CO}_{2}$ emissions per unit of energy consumption in all regions of China in 2019 as shown in Figure 13:

Figure 13, Regional energy unit emissions in 2019

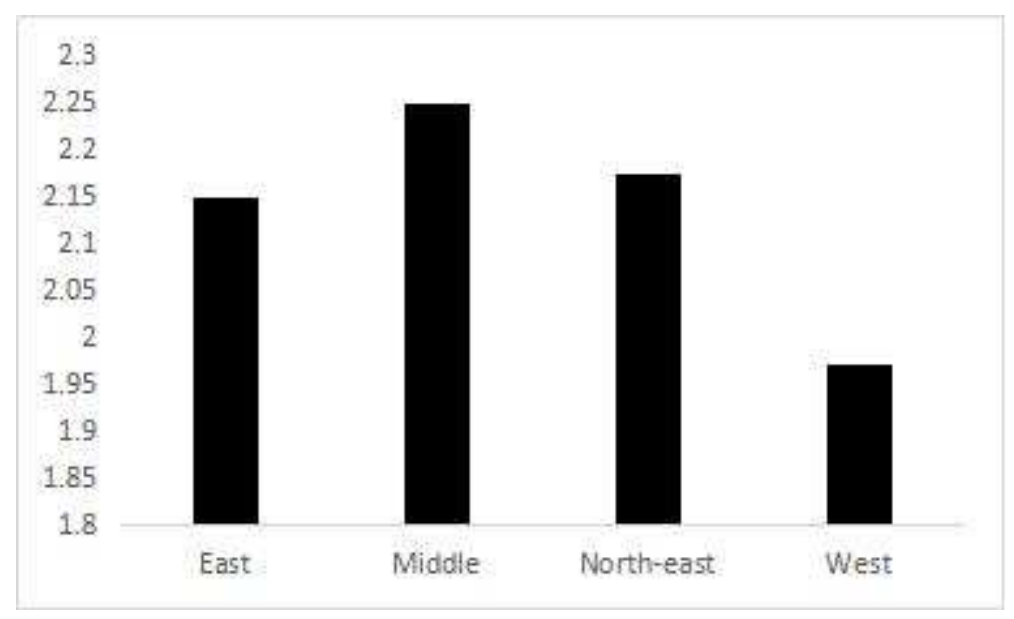

Figure 13 shows that the difference in $\mathrm{CO}_{2}$ emissions per unit of energy consumption in China's four regions is not large, namely 2.15, $2.03,2,17$, L98 tons / ton of standard energy.

According to the study background above, we designed the development scenario of the energy structure of the next four regions. $\mathrm{CO}_{2}$ emissions per unit of energy consumption is a comprehensive indicator of energy composition, and lower $\mathrm{CO}_{2}$ emissions per unit of energy consumption means cleaner energy composition. The Energy Technology Revolution Innovation Action Plan (2016-2030), released by 
the State Energy Administration, aims to achieve 20\% of China's total clean energy consumption by 2030. Yan Yu (2016) predicts that China's non-fossil energy, oil, natural gas and coal will account for $21 \%, 16.8 \%$, $11.9 \%$ and $50.3 \%$ of total energy consumption in 2030 , respectively. $3 \%$. For the construction of clean energy technology breakthrough scenario C1, we refer to the China Energy Research Association released the "China Energy Outlook 2030" forecast for the future development of energy structure, by 2030, China's non-fossil energy use will reach $22 \%$, coal use will fall below $50 \%$.

The Technology Stagnation Scenario (C4) assumes that the energy structure remains the same and that $\mathrm{CO}_{2}$ emissions per unit of energy consumption will be consistent with 2015 levels by 2030 . We will design a low-speed development scenario $\mathrm{C} 3$ for the energy structure as a baseline scenario (C2) and a technology stagnation scenario (C4) transition. Considering that energy can be traded between the four regions, we assume that the four regions will maintain the same rate of reduction in $\mathrm{CO}_{2}$ emissions per unit of energy consumption under the established scenario, and that the unexequested scenarios for the energy structure of the four regions are presented in table 6 .

Table 6, Regional energy structure development scenarios

\begin{tabular}{cc}
\hline Scenario & \multicolumn{1}{c}{ Instructions } \\
\hline & By 2030, China will have achieved a \\
& breakthrough in clean energy technology, \\
& with clean energy accounting for 22\% of
\end{tabular}


Technology breakthrough scenario (C1)

The baseline scenario

(C2)

Technology is slowly developing Scenario

(C3)

Stagnant scenario (C4) energy consumption, $17 \%$ of oil use, $12 \%$ of natural gas use and $49 \%$ of coal use.

Average annual reduction in $\mathrm{CO}_{2}$ emissions per unit of energy consumption in each region: $\mathrm{d}_{1}=1.05 \%$

By 2030, China's clean energy technology will develop steadily, with clean energy accounting for $21 \%$ of energy consumption and oil use reaching 16 . $8 \%$, the proportion of natural gas use reached $11.9 \%$, the proportion of coal use fell to $50.3 \%$.

Average annual reduction in $\mathrm{CO}_{2}$ emissions per unit of energy consumption in each region: $\mathrm{d}_{2}=0.95 \%$

By 2030, China's clean energy technology is developing slowly, and clean energy accounts for $16.55 \%$, the proportion of oil use reached $17.55 \%$, the proportion of natural gas use reached $9 \%$, the proportion of coal use fell to $57.0 \%$

Average annual reduction in $\mathrm{CO}_{2}$ emissions per unit of energy consumption in each region: $\mathrm{d} 3=0.46 \%$

By 2030 , the energy structure will remain unchanged from 2015.

\section{Peak scenario}

Based on the comprehensive analysis of economic growth, energy intensity and possible future changes in energy structure in various

594 regions, we have constructed $3 * 4 * 4=48$ scenarios for the future

595 development of China's carbon emissions. The peak and peak levels of

$596 \mathbf{C O}_{2}$ emissions in 48 scenarios are shown in Figure 14 . We can divide 59748 scenarios into five groups depending on when $\mathrm{CO}_{2}$ emissions peak, 


\begin{tabular}{cllll}
\hline Peak Scenario & B1 & B2 & B3 & B4 \\
\hline A1 & C1-4 & C1-3 & - & - \\
A2 & C1-4 & C1-3 & - & - \\
A3 & C1-4 & C1-3 & - & - \\
\hline
\end{tabular}

607 the increase in China's carbon dioxide emissions in the future is the 608 growth of China's oil and gas demand. According to the United Nations 609 (2011), Chinese will peak around 2027, before continued population 610 growth leads to demand for oil and gas, so the likelihood of $\mathrm{CO}_{2}$ 
611 emissions peaking by 2025 is low. Current researchers widely predict that 612 China's carbon dioxide emissions will peak between 2025 and 2030. If 613 China wants its carbon dioxide emissions to peak by 2025, it will need 614 strict demands on economic growth, energy efficiency improvements and 615 energy structure optimization.

616 Therefore, we define the peak scenarios for 2015 (peaks of about 9.3 617 billion tons) and 2020 (peaks of about 9.5 billion tons) as reference 618 scenarios. A scenario that peaks in 2025 (about 10 billion tons) and 2030 619 (about 11 billion tons) is defined as a viable scenario. Table 4 and 6 show 620 that each of China's economic growth scenarios has seven scenarios 621 corresponding to achieve the peak of carbon dioxide. If the efficiency of 622 energy utilization in the future is increased at a high rate in accordance 623 with the B1 scenario, then even if China does not optimize its energy 624 structure, the economy can achieve a high level of $\mathrm{CO}_{2}$ emissions. 625 However, if energy efficiency is low in the future (Scenario B3-4), even 626 in the context of a clean energy breakthrough, there is no scenario to 627 reach a peak by 2030 . It can be seen that the full improvement of energy 628 efficiency is very important to achieve the $2030 \mathrm{CO}_{2}$ emissions peak 629 target as shown in table 7.

\section{Results and discussions}


634 want to maximise expected output (GDP) and minimize non-expected 635 co-production $\left(\mathrm{CO}_{2}\right)$." The Centralized-DEA model is a linear planning 636 method for analyzing the efficiency of calculating resource allocation under resource constraints, proposed by Zhou and others, compared with traditional packet analysis, the Centralized-DEA model also considers the 639 impact of weak disposal of pollution emissions and regional development 640 base on regional carbon emission allocation efficiency, and has a better research effect on how to achieve the efficient allocation of carbon emission quotas between regions. In this article, we used this method to maximize China's desired yield in the context of a given amount of $\mathrm{CO}_{2}$ emissions. If $\mathrm{CO}_{2}$ emissions are allocated in 30 provinces and cities in China according to optimal quotas calculated by the Centraled-DEA model, higher distribution efficiency will be achieved, freeing up more economic output. The Highd-DEA model is shown in the same style (8):

$$
\operatorname{Max} \sum_{1=1}^{\mathrm{k}} \hat{y}_{1}^{t}
$$

$$
\mathrm{St} . \sum_{k=1}^{k} z_{k}^{t} x_{i k}^{t} \leq x_{i l}^{t} i=1, \ldots, m ; l=1, \ldots, k
$$

$$
\sum_{k=1}^{\mathrm{k}} z_{1}^{t} y_{1}^{t} \geq \hat{y}_{l}^{t}
$$

$$
\sum_{k=1}^{\mathrm{k}} z_{1}^{t} c_{1}^{t}=\hat{c}_{l}^{t}
$$

$$
\sum_{l=1}^{\mathrm{k}} c_{l}^{t}=\sum_{l=1}^{k} \hat{c}_{l}^{t}
$$

$$
\mathrm{z}_{k}^{t} \geq 0, \hat{y}_{l}^{t} \geq 0, \hat{c}_{l}^{t} \geq 0
$$


655 capital, people, energy); $\hat{\mathrm{y}}_{t}^{\mathrm{t}}$ and $\mathrm{y}_{t}^{t}$ present the best output of $\mathrm{CO}_{2}$ 656 emissions and actual $\mathrm{CO}_{2}$ emissions in 1 province during $\mathrm{t}$ period; $657 \mathrm{c}_{t}^{t}$ and $\widehat{\mathrm{c}}_{t}^{\mathrm{t}}$ present the best and actual disposition of $\mathrm{CO}_{2}$ emissions in 1 658 province during $\mathrm{t}$ period (Fare e.g., 2005). Finally, we maximize 659 the $\sum_{l=1}^{\mathrm{k}} \hat{y}_{l}^{k}$, which represents the greatest output of the country's 660 expectations.

661

Distribution efficiency and potential output capacity of the peak

663

664

665

666

667

668

669

670

671

672

673

674

675

676

scenario

To better compare the differences between regional carbon emission paths in different peak scenarios and regional carbon emission paths optimized by Centralized-DEA, and to evaluate the efficiency of carbon emission allocation, we introduced deviation indices to measure differences in $\mathrm{CO}_{2}$ emissions from each region before and after Each year, as shown in the model (9):

$$
\mathrm{d}(s)=\sum_{t=1}^{T} \sum_{l=1}^{k}\left|C_{l s}^{t}-\hat{C}_{l s}^{t}\right|
$$

In the formula (4-9), $K=30$ represents 30 provinces and cities; $T=25$ represents the time range studied spanning 25 years from 2016 to 2040; $\mathrm{c}_{l s}^{t}$ means $\quad$ l province's $\mathrm{CO}_{2}$ emissions during $\mathrm{t}$ period under scenario $\mathrm{s}$; $\widehat{\mathrm{c}}_{t \mathrm{~s}}^{\mathrm{t}}$ represents $\mathrm{l}$ province's $\mathrm{CO}_{2}$ emissions during $\mathrm{t}$ period under scenario $\mathrm{s}$ after the optimization of Centralized-DEA; $\left|\widehat{\mathrm{c}}_{t s}^{t}-\mathrm{c}_{s s}^{t}\right|$ is the absolute deviation of $\mathrm{c}_{t s}^{t}$ and $\widehat{\mathrm{c}}_{t s}^{\mathrm{t}}$; The lower $\mathrm{d}_{(\mathrm{s})}$ means that scenarios are 
more efficient in allocating carbon emissions.

We divide the optimized total yield of Centralized I-DEA under the established scenario (s) by the total carbon dioxide emissions, and arrive at $\mathrm{e}(\mathrm{s})$ to measure the potential yield capacity in each scenario, as shown in the model (4-10):

$$
\mathrm{e}(s)=\sum_{t=1}^{T} \sum_{l=1}^{K} \hat{Y}_{l s}^{t}
$$

In this way, we can understand the potential GDP size of each scenario under a given $\mathrm{CO}_{2}$ emissions scenario, and the higher the (S), the higher the potential output in that scenario.The $\mathrm{CO}_{2}$ distribution efficiency measurement reveals which scenario $\mathrm{CO}_{2}$ emission configuration is better able to boost GDP growth. Based on formula 4(8-10), we calculated a deviation index reflecting the efficiency of $\mathrm{CO}_{2}$ emission distribution in 21 peak scenarios, as shown in figure 15, in order for countries that reached the peak of carbon emissions earlier to allocate $\mathrm{CO}_{2}$ emission quotas more efficiently among regions.

As mentioned earlier, China is less likely to peak $\mathrm{CO}_{2}$ emissions by 2025 , so we should focus on analyzing the scenarios where carbon emissions will peak in 2025 and 2030, as shown in Figures 15, in 2025 and $2030 \mathrm{~A} 2 \mathrm{~B} 2 \mathrm{C} 1$ and $\mathrm{A} 1 \mathrm{~B} 2 \mathrm{C} 2$ have the lowest deviation indices, respectively, meaning that the $\mathrm{CO}_{2}$ emission path in the $\mathrm{A} 2 \mathrm{~B} 2 \mathrm{C} 1$ and A1B2C2 scenarios is closest to the optimal path optimized by Centralized-DEA. So the A2B2C1 and A1B2C2 scenarios are the most 
efficient for co2 emissions distribution in 2025 and 2030, respectively.

Figure 15, The deviation value of 21 peak scenarios

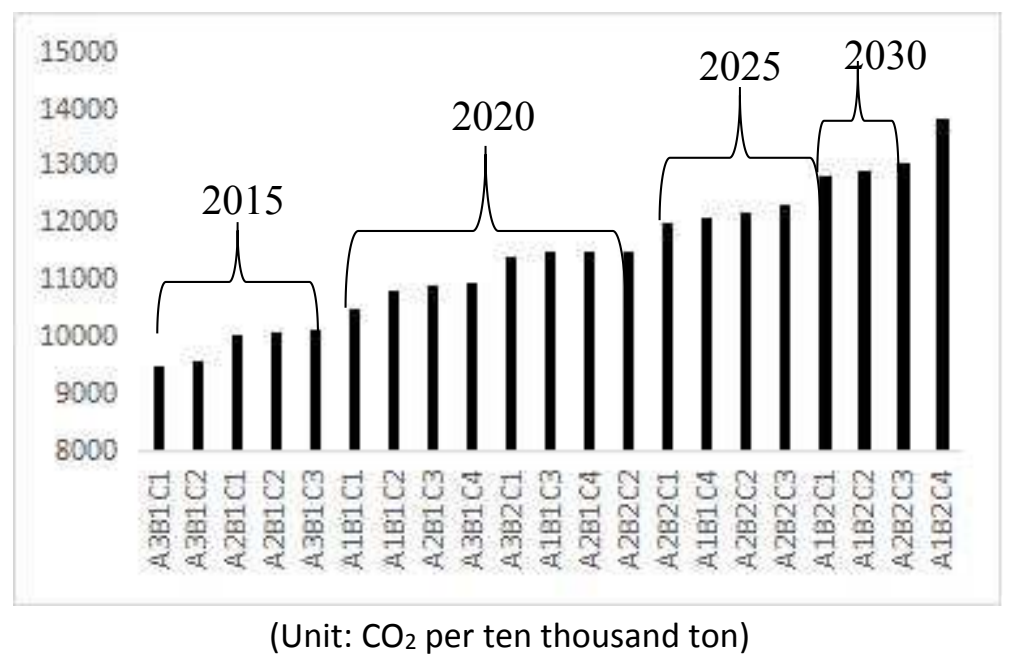

Using the maximum potential output per unit of $\mathrm{CO}_{2}$ emissions as an evaluation criterion (based on formulas 10), we further assessed the potential output efficiency of scenarios that peak in 2025 and 2030, as shown in Table 7, where scenario A1B2C2 has the highest potential emission efficiency in scenarios where carbon emissions peak by 2030. In the peak scenario in 2025 , A1B2C1 has more stringent requirements for optimizing the energy structure than $\mathrm{A} 1 \mathrm{~B} 2 \mathrm{C} 2$, and the potential output efficiency of $\mathrm{CO}_{2}$ emissions is slightly lower than that of Scenario $\mathrm{A} 1 \mathrm{~B} 1 \mathrm{C} 4$, which is approximately equal to A2B2. CU scenario A1B1C4 because there is no optimization of the energy structure (C4) and the optimization of energy efficiency requirements are higher (B1), neither realistic and difficult to achieve, the feasibility is poor, after excluding scenario $\mathrm{A} 1 \mathrm{~B} 1 \mathrm{C} 4$ can be inferred, $\mathrm{A} 1 \mathrm{~B} 2 \mathrm{C} 1$ and $\mathrm{A} 1 \mathrm{~B} 2 \mathrm{C} 2$ are the most efficient scenarios for potential $\mathrm{CO}_{2}$ emissions in 2025 and 2030, 
717 respectively. However, C2 is relatively less constrained to changes in 718 energy structure than $\mathrm{C} 1$, the $\mathrm{A} 1 \mathrm{~B} 2 \mathrm{C} 2$ scenario is easier to achieve than 719 the A1B2C1 scenario, and also meets China's commitment of $20 \%$ 720 non-fossil energy use by 2030 , providing more flexible space for policy 721 implementers, and the highest distribution efficiency in the peak scenario in 2030. Therefore, we chose the $\mathrm{A} 1 \mathrm{~B} 2 \mathrm{C} 2$ scenario, which will peak in

7232030 , as the optimal peak scenario for further analysis shown in table 8 . Table 8, Peak Scenario Potential Output Rankings

\begin{tabular}{cc}
\hline Peak time & $\begin{array}{c}\text { Top three rankings for potential output of } \\
\text { peak scenarios }\end{array}$ \\
\hline & A1B1C4 $(0.190)>\mathrm{A} 1 \mathrm{~B} 2 \mathrm{C} 1(0.181) \approx$ \\
& $\mathrm{A} 2 \mathrm{~B} 2 \mathrm{C} 1(0.180)$ \\
& \\
& $\mathrm{A} 1 \mathrm{~B} 2 \mathrm{C} 2(0.179)>\mathrm{A} 1 \mathrm{~B} 2 \mathrm{C} 3(0.168) \approx$ \\
& $\mathrm{A} 2 \mathrm{~B} 2 \mathrm{C} 3(0.167)$ \\
& \\
\hline
\end{tabular}

As can be seen from table 8 , in the optimal peak scenario, the eastern and north-eastern regions, after 2015, are redistributed by 728 Centralized-DEA with less optimal carbon emissions than the actual 729 carbon emissions. In the Middle, the optimal carbon emissions from 730 Centralized-DEA redistribution after 2015 are higher than actual carbon 731 emissions. As mentioned earlier, we have found that the GDP per capita 
in the East and Northeast is in the first and second place, respectively.

It can be found that in the optimal peak scenario, the economically developed East and Northeast regions should bear more responsibility for emission reduction, because the two regions have less room for emission reduction. Moreover, the allocation of carbon emissions to the less developed Middle and West regions can improve the efficiency of carbon emission distribution, creating more output. The economic development of the less developed West region should be allocated more carbon emissions rights, because of its current inefficient energy use, its potential energy marginal output of the increase in space.

\section{Optimal peak scenario characteristic analysis}

According to the analysis of $\mathrm{CO}_{2}$ distribution efficiency and potential output efficiency, $\mathrm{A} 1 \mathrm{~B} 2 \mathrm{C} 2$ is the optimal peak scenario to achieve China's carbon emission targets and international commitments. As shown in Table 8, in Scenario A1B2C2, China will continue to grow at a rapid rate of GDP, with GDP growing by $140 \%$ in 2030 compared to 2015 to 172.6 trillion yuan, and its GDP growth rate in 2016-2030 will similar to the data of World-Economic-Outlook-october-2019 as shown in table 9 and slightly lower than the benchmark designed by Yuan and other (2014) scenarios. GDP per capita will reach $\$ 176,000$ in 2030. 

development level under the optimal peak scenario

\begin{tabular}{|c|c|c|c|c|c|c|c|}
\hline Year & Metrics & Unit & China & East & Middle & North-east & West \\
\hline \multirow{3}{*}{2015} & GDP & $\begin{array}{c}\text { trillion } \\
\text { yuan }\end{array}$ & 72.17 & 37.3 & 14.7 & 5.78 & 14.4 \\
\hline & $\begin{array}{c}\text { GDP per } \\
\text { cptia }\end{array}$ & $\begin{array}{c}\text { ten } \\
\text { thousand } \\
\text { yuan }\end{array}$ & 5.28 & 7.10 & 4.03 & 5.28 & 3.91 \\
\hline & GDP & $\begin{array}{c}\text { trillion } \\
\text { yuan }\end{array}$ & 101.37 & 51.66 & $20 . \overline{85}$ & $\overline{7.98}$ & 20.88 \\
\hline \multirow[t]{2}{*}{2020} & $\begin{array}{l}\text { GDP per } \\
\text { cptia }\end{array}$ & $\begin{array}{c}\text { ten } \\
\text { thousand } \\
\text { yuan }\end{array}$ & 7.16 & 9.24 & 5.60 & 7.21 & 5.57 \\
\hline & GDP & $\begin{array}{l}\text { trillion } \\
\text { yuan }\end{array}$ & 135.87 & 68.39 & 28.19 & 10.53 & 28.77 \\
\hline \multirow{3}{*}{$\begin{array}{r}2025 \\
2030\end{array}$} & $\begin{array}{l}\text { GDP per } \\
\text { cptia }\end{array}$ & $\begin{array}{c}\text { ten } \\
\text { thousand } \\
\text { yuan }\end{array}$ & 9.49 & 11.78 & 7.62 & 9.67 & 7.73 \\
\hline & GDP & $\begin{array}{l}\text { trillion } \\
\text { yuan }\end{array}$ & 172.59 & 86.49 & 36.28 & 13.28 & 36.55 \\
\hline & $\begin{array}{c}\text { GDP per } \\
\text { cptia }\end{array}$ & $\begin{array}{c}\text { ten } \\
\text { thousand } \\
\text { yuan }\end{array}$ & 11.96 & 14.34 & 9.89 & 12.42 & 9.90 \\
\hline
\end{tabular}

(Data source: World-Economic-Outlook-october-2019, WEO 2019)

As a consequence, the next step is that we can allocate the 758 stimulating data from table 8 and combine it with the forecast data from the World Economic Outlook 2019 (which is shown in table 9) to achieve

760 the more exact data of China's four major regions' future economic 761 developing trend.

762 Peak time and peak of $\mathrm{CO}_{2}$ emissions

$763 \quad$ Northeast has always been China's oldest industrial base, although 764 the current level of economic development is high, but due to 
765

766 development is also one of the important drivers of regional $\mathrm{CO}_{2}$

767 emissions. The slow growth of the economy to reduce the growth rate of

over-reliance on heavy industry, GDP growth is slow, because economic $\mathrm{CO}_{2}$ emissions and the average annual population growth rate in the Northeast. The stable growth of population size will also make a regional energy consumption tends to stabilize, so it is easier for the Northeast to peak emissions relative to the Middle and West.

Figure 16, The peak time and statistic of $\mathrm{CO}_{2}$ in the $\mathrm{A} 1 \mathrm{~B} 2 \mathrm{C} 2$ scenario

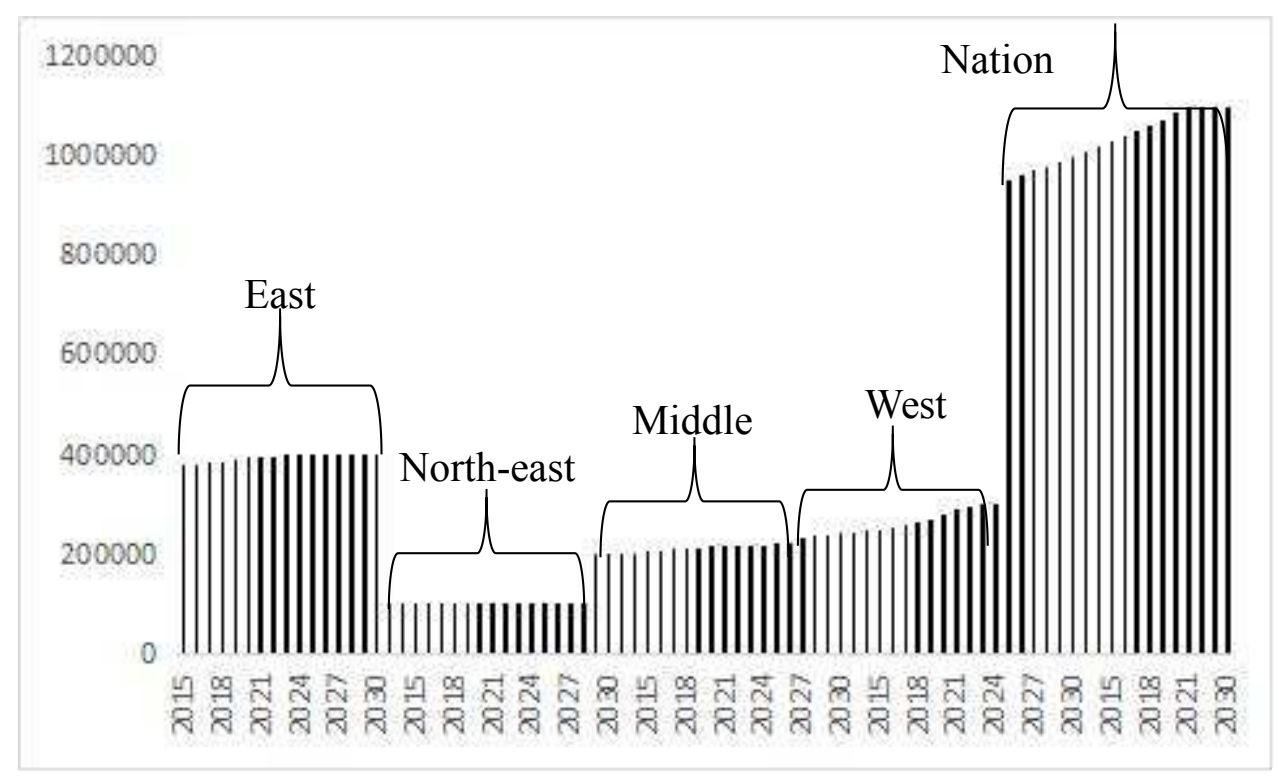

As shown in Figure 16, in scenario A1B2C2, China's CO2 emissions peaked at 10.57 billion tons in $2030 . \mathrm{CO}_{2}$ emissions from the East and Northeast peaked in 2025 and peaked in 2030 of the Middle and West . The East has the highest level of economic development, and the higher level of economic development also indicates a lower potential for economic growth. Compared with the lower level of economic 
development in the Middle and West, the GDP growth rate in the East is also low. According to the Kuznets curve theory, when a region's economic development to a certain stage, carbon emissions may decrease, because of the high level of economic development. Therefore, the East's economic development process is closer to the Kuznets U-shaped curve inflection point, so the East is more likely to reach the peak.

In addition, the economic development degree of the Middle and West is low, the relationship between economic development and carbon emissions is closer to the first half of the Kuznets U-shaped curve, with the release of future economic development potential and the improvement of economic level. Economic development on the growth of carbon dioxide emissions will gradually decline, so the Middle and West need to achieve $\mathrm{CO}_{2}$ emissions peak at a slower rate.

\section{Peak time and peak of carbon dioxide per capita}

As shown in Figure 17, in Scenario A1B2C2, the country's per capita $\mathrm{CO}_{2}$ emissions will peak in 2025, peaking at 6.96 tons. The East peaked in 2015, the Northeast peaked in 2025, and the Middle and West regions will not peak until 2030.

Moreover, the table 10 shows that the higher the level of economic development in the four regions, the sooner the per capita carbon dioxide emissions peak. The four regions had the highest $\mathrm{CO}_{2}$ emissions in the 
803 Northeast and West, at 81 tons and 36 tons, respectively. The peak per 804 capita $\mathrm{CO}_{2}$ emissions in the eastern region will be earlier than their $\mathrm{CO}_{2}$ 805 emissions peak, a phenomenon caused by the high population growth rate 806 in the eastern region (see Table 10). Zhu and others (2001) found that 807 cross-provincial population growth was concentrated in the economically 808 developed eastern regions. We can infer that rapid population growth will 809 be one of the main reasons for delaying the peak of $\mathrm{CO}_{2}$ emissions in the 810 eastern region. Table 10, Average population growth rate

\begin{tabular}{ccccc}
\hline Region & East & Middle & North-east & West \\
\hline $\begin{array}{l}\text { Population } \\
\text { growth rate }\end{array}$ & $1.24 \%$ & $0.37 \%$ & $0.18 \%$ & $0.33 \%$ \\
\hline
\end{tabular}
scenario

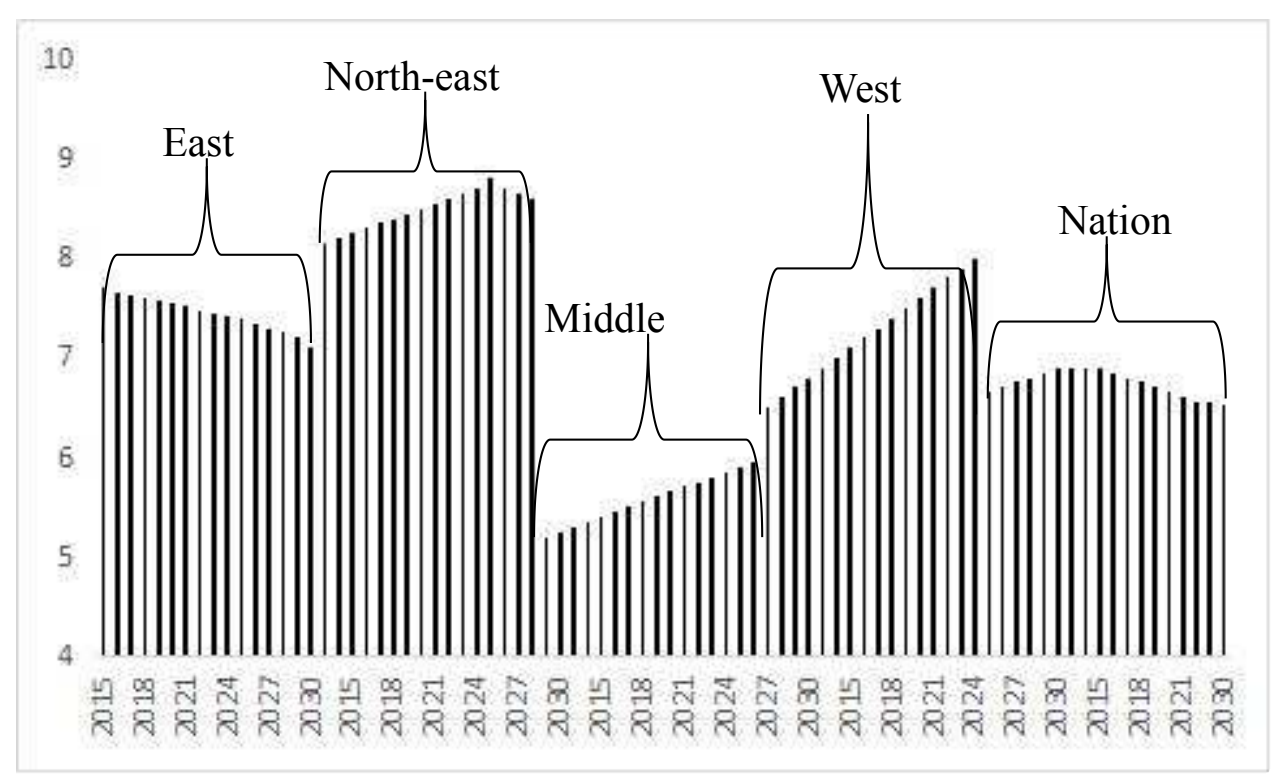


818 lower in 2030 than in 2015.

\section{The magnitude of the decrease in carbon intensity}

It is clear that the reduction in carbon intensity in the optimal scenario is much greater than our current emission reduction targets, and

823 that the reduction in carbon intensity in the optimal scenario is similar to 824 the results in the ambitious scenarios in the Liu and other (2018) 37 studies, i.e. by 2020 and 2030 Carbon intensity is $52.54 \%$ lower than 2005 levels and $71.36 \%$ lower than 2005 levels, respectively) did not

827 effectively limit global warming to 2 degrees Celsius. Stern and Green 828 (2015) point out that it would be more effective for China to set a target 829 of reducing carbon dioxide emissions by less than 10 billion tons (less 830 than 7 tons per capita) by 2030 to keep global warming within 2 degrees 831 Celsius. Therefore, setting stricter carbon intensity reduction targets is 832 particularly important to prevent global warming and ensure that carbon 833 emissions peak by 2030 , as shown in table 11 .

Table 11, Industrial energy intensity and energy structure

\section{Average annual decline in energy}

intensity 2005-2015 (\%)

$3.73 \%$

$3.42 \%$

$1.12 \%$ 
Energy intensity in 2015

(tons of standard coal / 10,000

yuan)

Industrial structure in 2015 (\%)

$$
\begin{array}{lll}
8.8 \% & 40.9 \% & 50.2 \%
\end{array}
$$

Average energy intensity in 2015

(tons of standard coal / 10,000 yuan)

Average annual decline in energy

intensity 2016-2030 (\%)

$3.73 \%+0.5 \% \quad 3.42 \%+0.6 \%$

$1.12 \%+0.6 \%$

Industrial structure in $2030(\%)$

$\begin{array}{lll}8 \% & 32 \% & 60 \%\end{array}$

Average energy intensity in 2030

(tons of standard coal / 10,000

yuan)

Rate of decline during energy

$45 \%$

intensity 2016-2030 (\%)

As can be known from table 10, the average annual decline in energy intensity in the first, second and third industries in 2010-2019 was $3.73 \%, 3.42 \%$ and $1.12 \%$, respectively. If the rate of decline in energy intensity of various industries increases by $0.5 \%, 0.6 \%$ and $0.6 \%$ in the future, the industrial structure will develop like Li Cedar and so on (2016)

841 Year will reach $8 \%, 32 \%, 60 \%$, China's energy intensity will be reduced 842 by $45 \%$ compared to 2015 , with the optimal situation A1B2C2 convergence, but lower than Yuan and other (2014) forecast. At the same

844 time, the decline in energy intensity under the optimal scenario is lower 845 than the historical (2005-2015) downward trend, so in improving the 846 efficiency of energy use in various industries, but also to speed up the 
optimization of industrial structure, enhance the proportion of output value of the tertiary industry in total output. In addition, if the energy structure is optimized, it is in line with Liu (2018). It is predicted that by 2030, non-fossil energy sources will account for $21 \%$ of China's energy consumption o China's carbon intensity will be 53.46 percent lower than in $2015,72.7 \%$ lower than in 2005 , exceeding the emission reduction target of $60 \%-65 \%$.

\section{Study on the impact factors of carbon emissions in four regions based} on history and future

In this section, we will analyze the contribution of the $\mathrm{CO}_{2}$ emission path from 2009-2030 using the broad Dix index decomposition method to the various $\mathrm{CO}_{2}$ influence factors based on the optimal scenarios analyzed and find out the absolute contribution of the influence factors of regional historical trends (2006-2015) and forecasting trends (2016-2030).

As we can see from Figure 18-21, the absolute contribution of carbon emission factors in the four regions is very similar in size, but slightly different. Among the four regions, economic scale contributes the most to the growth of $\mathrm{CO}_{2}$, while low carbon per unit of output contributes the most to $\mathrm{CO}_{2}$ emission reduction, and energy efficiency, energy composition, economic development level and population size all contribute less to $\mathrm{CO}_{2}$ emissions. 
870 Analysis of the impact of economic regulation and economic 871 development

872 Figure 18 shows that from 2006 to 2030, in addition to the West in 873 the period of $2011-2015$, the contribution of economic regulations to 874 carbon emissions increased slightly, whether historical trends or forecast 875 trends, the contribution of GDP to carbon emissions in the four regions 876 has been decreasing annually. It shows that the contribution of economic 877 scale to carbon emission growth under the optimal peak path will 878 gradually decline.

879 During this period, the contribution of the four regional economic 880 development levels to carbon emissions is directly negative, indicating 881 that the improvement of regional economic development level does 882 contribute to the reduction of carbon dioxide emissions. But in the 883 historical interval and forecast range, the contribution of economic 884 development level to carbon emission reduction is small, indicating that 885 even under the optimal peak path, the improvement of economic 886 development level is not the main factor driving carbon dioxide emission 887 reduction. 
Low carbon per unit of output, also known as carbon intensity,

892 China currently plans to reduce carbon intensity by $60 \%$ to $65 \%$ by 2030

893 compared with 2006 . This index is one of the main reference objectives 894 of China's emission reduction policy.

Figure 18-21 show that carbon intensity contributes the most to $\mathrm{CO}_{2}$ emissions reductions in the four regions, both in the regional historical range (2006-2015) and in the forecast range (2016-2030), while energy 898 efficiency and energy structure contribute less. Thus, carbon intensity can 899 be derived from the product of energy consumption per unit of GDP and carbon emissions per unit of energy consumption, which means the low 901 carbon output per unit of output in the region is affected by the region's 902 energy efficiency and energy structure, so we can infer that the indirect emission reduction contribution of energy efficiency and energy source 904 structure is greater than its direct contribution, which should be attributed 905 to the development of low-carbon production technology. Furthermore, 906 the production of the same output value with less and less expected 907 output, the low-carbon effect of economic development energy efficiency 908 and optimization of energy structure will become more and more 909 prominent. Therefore, it is particularly important to accelerate the 910 upgrading of industrial structure in major regions, complete the 911 transformation of medium- and high-carbon industries to low-carbon 912 industries, and increase the development and introduction of low-carbon 
913 production technologies to achieve indirect emission reduction 914 contributions to energy efficiency and energy structure optimization.

915

916 Analysis of the scale of energy consumption and the impact of carbon

917

918

919

920

921

922

923

924

925

926

927

928

929

930

931

932

933

dioxide per capita

From Figure 18-21, it is also easy to see that the four regions, whether in the regional historical range (2006-2015) or in the forecast range (2016-2030), the scale of energy consumption and the pull of carbon dioxide per capita on carbon emissions are declining, and the per capita $\mathrm{CO}_{2}$ emissions in the East and Northeast regions have even contributed to emission reductions between the forecast areas. It can also be found that in the historical range, the scale of energy consumption and the absolute value of the contribution of carbon dioxide per capita during the 12th Five-Year Plan period compared with the 11th Five-Year Plan period, indicating that the clear emission reduction policies set during the 12th Five-Year Plan period have a better effect on curbing energy consumption and the growth of carbon emissions per capita.

\section{Population size impact analysis}

By Figure 18-21, the four regions are either in the historical range of each region (2006-2015) or in the forecast range (2016-2030), The contribution of the factors of population size change to the change of 
935 936 have contributed less to the change of population size in the forecast 937 range, possibly because the factors of aging are taken into account in the 938 prediction of population data, and the change in the growth of Chinese 939 mouths is relatively small.

carbon dioxide is small, and all three regions except the eastern region

As a result, population changes contribute less to carbon emissions. On the other hand, due to the economic development and environment in the East is better (the highest level of economic development and the lowest low carbon per unit output value), and urbanized water level is higher, good economic development and environment for the population adsorption effect, population growth is slightly higher than the other three regions, and faster population growth will lead to more carbon demand, which will provide a positive contribution to the increase in carbon emissions.

Finally, due to the high level of urbanization in the East and the low level of urbanization in other regions, there may be a shift in the lifestyle of more people to a low-carbon lifestyle in the future urbanization process, which will make a positive contribution to regional emission reduction.

Figure 18, Contribution of $\mathrm{CO}_{2}$ influence factors in the Eastern region under the optimal peak scenario 
956

957

958

959

960

961

962

963

964

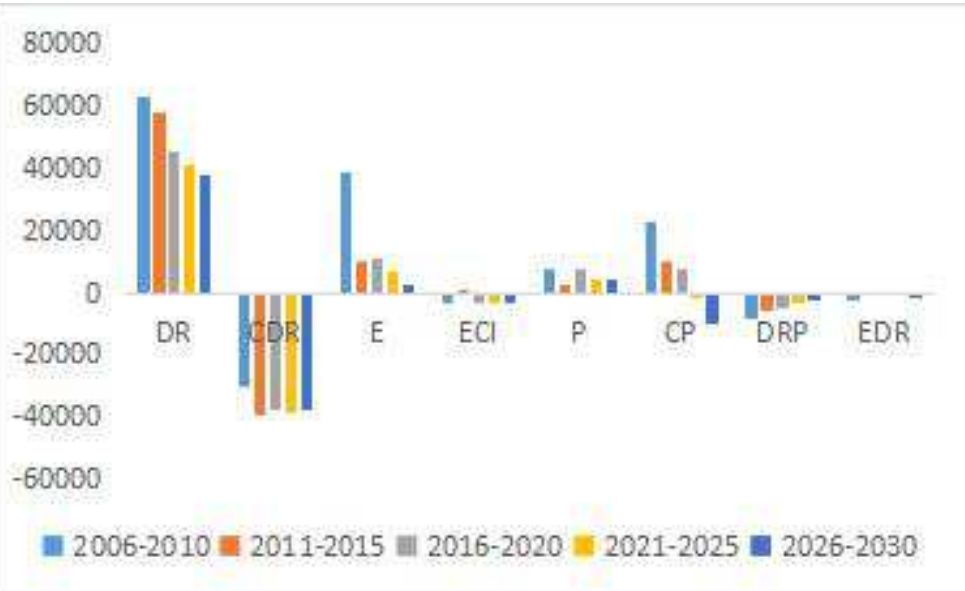

Figure 19, Contribution of $\mathrm{CO}_{2}$ influence factors in the North East region under the optimal peak scenario

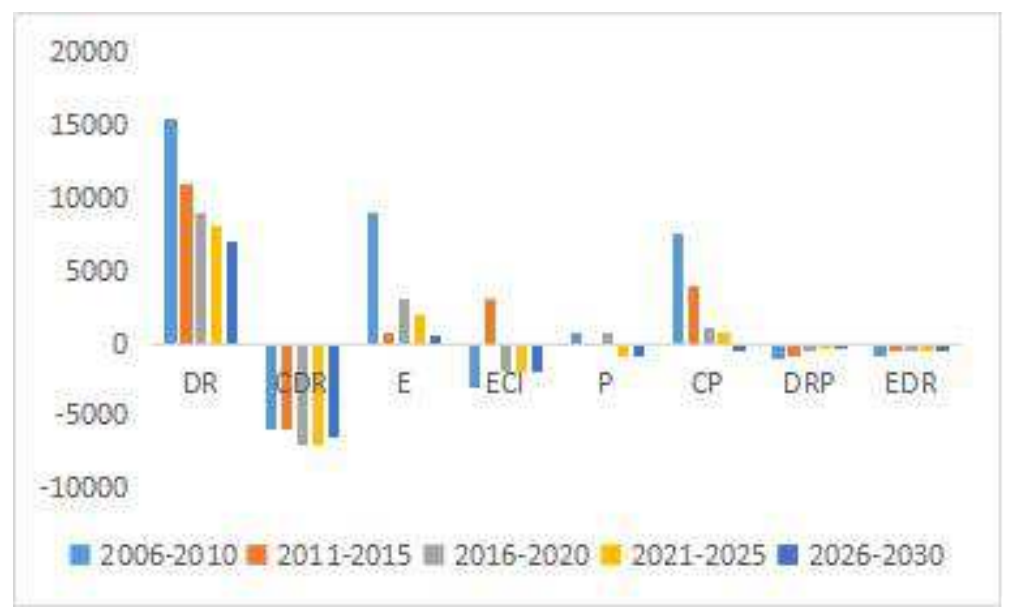

Figure 20, Contribution of $\mathrm{CO}_{2}$ influence factors in the Middle region under the optimal peak scenario 

976 development, based on the regional coordination development strategy of 977 the four major sectors implemented in recent years, this paper reviews the 978 historical trend of economic, population, urbanization and carbon
Figure 21, Contribution of $\mathrm{CO}_{2}$ influence factors in the Western region under the optimal peak scenario

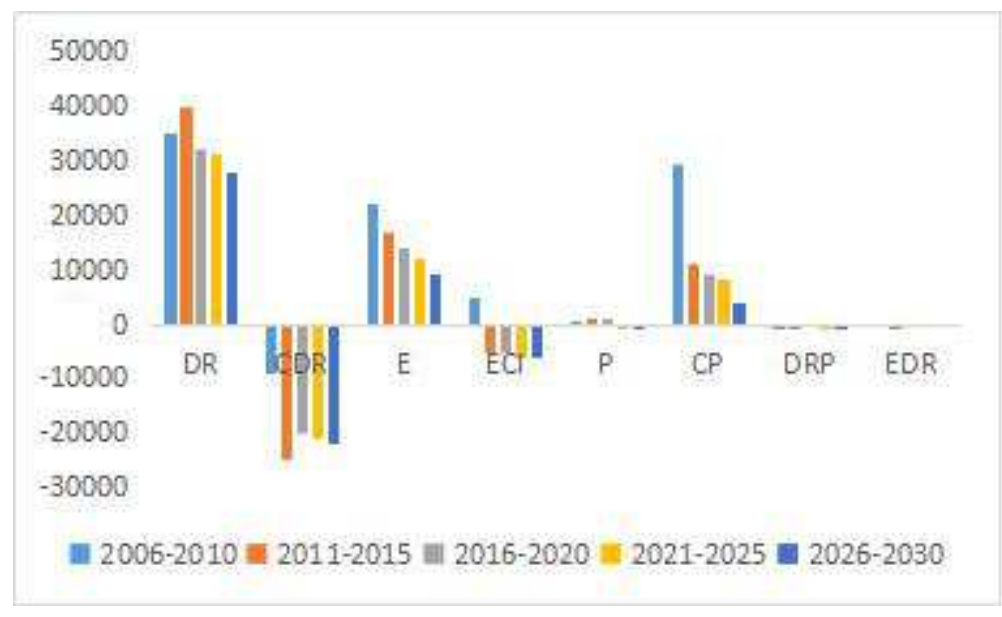

\section{Conclusions}

This paper devotes itself to studying the concrete way for China to achieve its 2030 carbon emission peak and corresponding emission reduction targets. Considering the heterogeneity of China's regional 
emission development in the four regions, and draws a number of scenarios for china's four major regions using scenario analysis and IPAT models combined with the forecast of authoritative institutions. Using The Centralized-DEA analysis method is used to evaluate the distribution efficiency and potential output efficiency of each peak scenario, and combined with the feasibility analysis, it is concluded that the optimal peak scenario $\mathrm{A} 1 \mathrm{~B} 2 \mathrm{C} 2$ with both distribution efficiency and potential output efficiency is compared according to the carbon emission path of the area before and after the optimal scenario Centralized-DEA, and we find that the focus points of different regional emission reduction policies should be different. In order to better identify the evolution of the contribution of carbon emission factors in the region in the process of achieving peak, we used the broad Di's index decomposition method to dynamically analyze the contribution of carbon emission influence factors in the historical and forecasting ranges of the four regions. Through our analysis of the current situation of carbon emission development and optimal peak path in the four regions above, we draw the following conclusions.

When economic development reachs a higher level, there is no obvious positive correlation between $\mathrm{CO}_{2}$ emissions per capita and the level of economic development. By comparing the Kuznets curves in the four regions, this paper finds that the positions of the environmental 
Kuznets curves in each region are not consistent, but they are stable with the development of economy. The environmental Kuznets curve in the north-east region is at the top, which means that its economic development path is the least environmentally friendly, while the central region has the most environmentally friendly economic development path at the same level of economic development.

Through international comparison of the environmental Kuznets curve, it is found that even if China's GDP continues to grow at a high rate, China's carbon emissions are more likely to reach the peak target of 2030.

Energy intensity is a key determining factor in achieving a peak in $\mathrm{CO}_{2}$ emissions. If the average annual rate of decline in energy intensity continues at China's 2009-2019 average, carbon emissions in all relevant scenarios will reach the peak target of 2030 . If China's energy intensity is no higher than 2.5\% down-rate development (B3 and B4), even if the energy structure optimization achieves the optimal scenario $(\mathrm{C} 1)$, the economy is growing at a low rate (A3), China's carbon dioxide will not peak by 2030 .

When China maintains high economic growth (AI scenario), energy intensity decline rate increases at the rate of $75 \%$ of China's average annual energy intensity decline rate from 2009 to 2019 (B2 scenario), and energy structure adjusts according to the forecast of the Energy 
Technology Revolution Innovation Action Plan (2016-2030), through the analysis of $\mathrm{CO}_{2}$ allocation efficiency and potential output efficiency, combined with previous studies and feasibility analyses The AIB2C2 scenario will be the best way to achieve China's carbon emissions targets and international commitments. In the optimal peak scenario, China's carbon dioxide emissions will peak at 10.57 billion tons by 2030, while China will enter high-income countries by 2024 .

Emission reduction space varies from region to region. In the forecast range of the optimal scenario, China's provincial carbon dioxide emissions will conver generally conver below average, and the eastern region will encounter bottlenecks in improving carbon intensity. At the same time, the Central and Western regions have more room to reduce carbon dioxide emissions, and increasing their $\mathrm{CO}_{2}$ emission quotas will free up more potential production.

Economically developed areas will peak earlier. Under the optimal scenario, the higher the level of economic development in the four regions, the sooner the per capita $\mathrm{CO}_{2}$ emissions and $\mathrm{CO}_{2}$ emissions peak the country's per capita $\mathrm{CO}_{2}$ will take precedence over the carbon dioxide peak, population growth will be the main reason for delaying the peak of $\mathrm{CO}_{2}$ emissions in the eastern region and the country. The east and north-east will peak carbon emissions by 2025 and the central and western regions by 2030 . 

based on history and future, this paper finds that the absolute contribution 1047 of the four regions' influence factors is very similar in size, but slightly 1048 different. Of the four regions, economic scale contributes the most to the 1049 growth of $\mathrm{CO}_{2}$ emissions, while low carbon per unit of output contributes 1050 the most to $\mathrm{CO}_{2}$ emission reduction. Changes in energy efficiency, energy 1051 structure, economic development, and population size all contribute less 1052 to $\mathrm{CO}_{2}$ emissions. In the historical trend, the regional economic scale, 1053 unit output value low carbon degree, energy consumption, per capita 1054 carbon emissions have contributed to the change of $\mathrm{CO}_{2}$ emissions, and 1055 under the future path of the optimal scenario, only the economic scale, 1056 low carbon per unit output value have a greater contribution to the change of $\mathrm{CO}_{2}$ emissions. 
Authors' contributions The authors contributed to the study conception and design. Material preparation, search, and collection of relevant articles and reviews were performed by Dawei Wang and Wenxing Shen. The first draft of the manuscript was written by Dawei Wang. Wenxing Shen and Shengliang Zhang thoroughly checked the first draft. All authors have read and approved the final manuscript.

\section{Declarations}

1083 Availability of data and materials All the data and materials in the manuscript are resourced from our research and analysis, so they all can

1085 be Guaranteed available, creditable and editable.

1086 Ethics approval and consent to participate Not applicable

1087 Consent of publication Not applicable

Competing interests Not applicable 


\section{References:} througli decomposition^.Energy, ,23(6):489-495.

1100

Ben C.N, Ben Z.Y, Chevallier J., 2021. On the nonlinear relationship between energy use and CO2 emissions within an EKC framework: Evidence from panel smooth transition regression in the MENA region[J]. Research in International Business and Finance, 55(prepublish).

1104

1105

British Petroleum, 2018. Energy Outlook 2018.

1106 https:/www.bp.com/content/dam/bp/business-sites/en/global/corporate/pdfs/energy-econmics/ ergy-outlook/bp-energy-outlook-2018.pdf.

1108

1109 Chai, Q.M., Xu, H.Q., 2014. Modeling an emissions peak in China around 2030: Synergies or trade-offs

1110 between economy, energy and climate security[J]. Advances in Climate Change Research 5(4):169-180.

1112 'China’s Energy Outlook 2030', Published Report [J]. Resource conservation and environmental protection. 2016fNo.173(04):6. 
Chavaillaz Y, Partanen A.I, et al. 2019. Exposure to excessive heat and impacts on labour productivity linked to cumulative $\mathrm{CO}_{2}$ emissions[J]. Scientific reports, 9(1): 1-11.

Commoner, B., 1972. The environmental cost of economic growth [J]. Chemistry in Britain 8(2): 52-56.

1119

Churchill, S.A., Inekwe, J. Ivanovski, K., Smyth, R., 2018. The environmental Kuznets curve in the OECD: 1870 - 2014[J], Energy Economics.

Dietz T, Rosa E A. 1997. Effects of population and affluence on CO2 emissions[J]. Proceedings of the National Academy of Sciences, 94(1): 175-179.

Du, K.R., Xie, C.P., Ouyang, X.L., 2017. A comparison of carbon dioxide $\left(\mathrm{CO}_{2}\right)$ emission trends among provinces in China[J]. Renewable and Sustainable Energy Reviews 73: 19-25.

Ebohon O J, Iketne A J. 2006. Decomposition analysis of $\mathrm{CO}_{2}$ emission intensity between oil-producing and non-oil-producing sub-Saharan African countries [J]. Energy Policy, 34(18): 3599-3611. greenhouse gas inventories (Vol. 5). Hayama, Japan: Institute for Global Environmental Strategies. practice[J]. Journal of Econometrics 126(2): 469-492. 
Gambhir A, Tse LKC, Tong D, Martinez-Botas R. 2015. Reducing China's road transport sector $\mathrm{CO}_{2}$ emissions to 2050: technologies, costs and decomposition analysis [J]. Applyed Energy, 157:905-17.

1147 emissions in east and south coastal China: Commonality and variations[J]. Journal of Cleaner Production $135: 240-250$.

Green F, Stern N. 2015. China's' new normal': structural change, better growth, and peak emissions[M]. Centre for Climate Change Economics and Policy. emissions from 1980 to 2030. Proceedings of the National Academy of Sciences of the United States of America [J]. Global Environmental Change 18(4): 626-634.

Guo, X.D., Zhu, L., Fan, Xie, B.C., 2011. Evaluation of potential reductions in carbon emissions in Chinese provinces based on environmental DEA[J]. Energy Policy 39(5): 2352-2360. Advances in Climate Change Research 5(4): 155-161. 
IMF, 2019. World Economic Outlook Databases. https://www.im f*org/en/Publications/SPROLLS/world • economic-outlook-databases.

International Energy Agency, 2014. World energy outlook 2010. https://www.iea.org/newsToom/ news/2010/novgmbef/world · erLergy-outlook-2010.html.

Kaika, D., Zervas, E., 2013. The environmental Kuznets curve (EKC) theory—Part A: concept, causes and the CO2 emissions case[J]. Energy Policy 62:1392-1402. scenarios. IPCC Energy and Industiy Subgroup, Response Strategies Working Group, Paris. OECD countries by level of globalization[J]. International Economics, 164. energy consumption and carbon emission of Chongqing[J]. Energy Procedia 61; 2596-2599. emissions across provinces in China [J].Journal of Cleaner Production 141: 1428-1444. 
1196 Liu, Q.L., Lei, Q., Xu, H.M., Yuan, J.H., 2018. China's energy revolution strategy into 2030. Resources[J],

1197 Conservation and Recycling 128: 78-89.

1198

1199 Liu, Z., 2016. China*s Carbon Emissions Report 2016. Harvard Kennedy School, Cambridge.

Ma D., Chen W., 2017, China's carbon emissions peak path-based on China TIMES model. Journal of

Tsinghua University(Science and Technology), 57(10): 1070-1075.

1203

McKinsey, 2009. China's green revolution: Prioritizing technologies to achieve energy and environmental sustainability. McKinsey \& Company, Beijing.

Miao, Z., Geng, Y., Sheng, J.C., 2016. Efficient allocation of $\mathrm{CQ}_{2}$ emissions in China; A zero sum gains data envelopment model[J]. Journal of Cleaner Production 112: 4144-4150.

1209

Olale, E., Ochuodho, T.O., Lantz, V, El Armali, J., 2018. The environmental Kuznets curve model for 1211 greenhouse gas emissions in Canada[J]. Journal of Cleaner Production 184,:859 868 .

Ozokcu, S., Ozdemir, 0., 2017. Economic growth, energy, and environmental Kuznets curve[J]. Renewable and Sustainable Energy Reviews 72,:639 647.

Quah, D., 1997. Empirics for growth and distribution: Stratification, polarization, and convergence clubs[J]. Journal of Economic Growth 2(1): 27-59. 
Tenaw D, Beyene A D., 2021. Environmental sustainability and economic development in sub-Saharan Africa: A modified EKC hypothesis[J]. Renewable and Sustainable Energy Reviews, 143.

Shao S, Liu J, Geng Y, et al., 2016. Uncovering driving factors of carbon emissions from China's mining sector [J]. Applied Energy, 166: 220-238.

Silverman B W. , 1986. Density estimation for statistics and data analysis[M]. CRC press.

Stem, D.I., 2015. The environmental Kuznets curve after 25 years[J]. Journal of Bioeconomics 19(1): 1-22.

UNFCCC, 2017. Greenhouse Gas Inventory Data, http://di.unfbcc.int/detailed_data_by party.

\section{UNPD. 2011. World population prospects: the 2010 revision [J].}

Vaninsky, A., 2014. Factorial Decomposition of $\mathrm{CO}_{2}$ Emissions: A Generalized Divisia Index Approach [J]. Energy Economics,(45) : 389-400.

Wang, C.J., Zhang, H.O., Ye, Y.Y., Su Y.X., Chen, W.L., 2014. Analysis of Influencing Mechanism of Carbon Emissions in Guangdong Province Based on the IO_-SDA Model[J]. Tropical Geography, 37(1): $10-18$.

Wang, X.L. 2017. Study on peak carbon emission prediction and comprehensive control strategy in Inner Mongolia Autonomous Region [D]. China University of Geology, 84-89.

Wang Z.H, Yu M.J., 2019. Factor Decomposition of Affecting Carbon Dioxide Emissions in China’s Petrochemical Industry: Based on Generalized Divisia Index Method[J]. Research on science and technology management, 39(24):26X274. 
1250 World Bank, 2012. China 2030: Building a modem, harmonious, and creative high-income society.

Xu, L. Chen, N.C., Chen, Z.Q., 2017. Will China make a difference in its carbon intensity reduction targets by 2020 and 2030?[J]. Applied Energy 203: 874-882. provinces[J]. Habitat International 49: 212-220.

Yuan, J., Xu, Y., Hu, Z., Zhao, C., Xiong, M., Guo, J., 2014. Peak energy consumption and $\mathrm{CO}_{2}$ emissions in China[J]. Energy Policy 68(2): 508-523. province: An expanded IPAT approach [J]. Applied Energy 112: 1510-1517. floating population in China[J], Acta Geographica Sinica 56(5):549-560. outlook to 2050: Perspectives from bottom-up energy end-use model [J]. Energy Policy 53:51-62. 
1276 performance [J]. Ecological Economics 60(1): 111-118.

1277

1278 Zhou, R, Sun, Z.R., Zhou, D.Q., 2014. Optimal path for controlling $\mathrm{CO}_{2}$ emissions in China: A perspective 1279 of efficiency analysis[J]. Energy Economics 45: 99-110.

1280 